\title{
Estimating Household Responses to Trade Reforms. Net Consumers and Net Producers in Rural Mexico*
}

\author{
Guido G. Porto ${ }^{\dagger}$ \\ Department of Economics \\ Universidad Nacional de La Plata
}

September 2015

\begin{abstract}
This paper explores an empirical methodology to assess the impacts of trade reforms in agriculture on household behavior in developing countries. I focus on consumption and income responses: when price reforms take place, households modify consumption and production decisions and local labor markets adjust. The paper proposes a joint estimator of demand and wage price elasticities from survey data. The method uses an empirical model of demand to extract price information from unit values, and uses this information to estimate the response of households to price reforms. By correcting unit values for quality effects and measurement error, the method overcomes the problem of the endogeneity of unit values. By endogeneizing household income, the model corrects potential biases in the estimation of own- and cross-price elasticities in consumption. I apply the method to an expenditure and income survey for rural Mexico. It is shown that the corrections suggested in this paper are empirically important. In particular, I show that allowing for consumption and income responses is a key element of an accurate empirical assessment of trade policy.
\end{abstract}

JEL Codes: F13, F14, F16

Keywords: agricultural trade reforms, welfare and poverty impacts of trade policy

\footnotetext{
*The outstanding research assistance of Jorge Balat is greatly appreciated. I am indebted to A. Deaton, P. Goldberg and G. Grossman for comments and early encouragement. I thank I. Brambilla, S. Galiani, D. Lederman, A. Nicita, M. Olarreaga, W. Sosa Escudero and A. Tarozzi for useful discussion at different stages of this research program, and participants in several seminar presentations. Special thanks go to A. Nicita, who shared the data on Mexico with me. I assume full responsibility for all the errors and omissions. I am also grateful to the R4D program for Research on Global Issues for Development funded by Swiss National Science Foundation and the Swiss Development Cooperation.

${ }^{\dagger}$ Guido Porto, Universidad Nacional de La Plata, Calle 6 e/47 y 48, 1900 La Plata, Argentina. email: guido.porto@depeco.econo.unlp.edu.ar
} 


\section{Introduction}

Trade in agricultural products is perhaps one of the most promising instruments for poverty alleviation in developing countries. This is because agriculture is a key productive activity in poor countries and because world markets can provide new opportunities for rural producers. However, international markets for agricultural products have long been distorted by the policies of developed countries. Policies of domestic support, such as subsidies to production or exports, and policies of market access, such as tariffs and non-tariff barriers, are examples. Understanding and measuring the impacts of WTO reforms on poor households in developing countries is therefore critical to the current trade and poverty debate.

When price reforms are implemented, particularly in agriculture, households are affected both as consumers and as income earners. The standard proposition of the literature is that, after an increase in the price of a good, net consumers will be worse off but net producers will be better off (Deaton, 1989). In this static context, the welfare effects of a price change can be assessed by comparing budget shares and income shares. This argument, however, fails to consider dynamic household responses. Consumers may respond by substituting away from the more expensive goods. In rural areas, farmers may increase agricultural production, farm employment and wages, and purchases of inputs and services in local markets. In consequence, the net position of the household becomes endogenous: sufficiently large consumption and income responses may cause an ex-ante net consumer become an ex-post net producer, thus benefiting from the price increase.

The measurement of the total household welfare effect, one that jointly considers first order effects in consumption and production as well as consumption and income responses, is the objective of this paper. I propose a joint estimator of demand price-elasticities and agricultural wage price-elasticities from survey data. The empirical method delivers a set of parameters that can be used to simulate policy outcomes and evaluate trade reforms. While my emphasis in this paper is on trade reforms in agriculture, the model can be used to investigate other pricing policies that affect tradable goods. ${ }^{1}$

\footnotetext{
${ }^{1}$ Sometimes, modern methods for policy evaluation like natural experiments are not feasible. Trade reforms, which are often accompanied by other simultaneous reforms, are an example. In many instances, in addition, there is an interest, or a need, to explore the effects of a policy that has not yet taken place.
} 
The estimation of these parameters requires survey data with sufficient price variation at the household level. This is rarely the case. One possibility is to combine household surveys with official price information. Some studies exploit time and regional variation in official prices (Deaton, 1997; Porto, 2006; Ravallion, 1990; Wolak, 1996); others use community price questionnaires (Edmonds and Pavcnik, 2005; 2006). In this paper, I use unit values, the ratio of reported expenditures and quantities, as measures of prices.

The main advantage of using unit values in household models is the substantial cross-sectional variability. However, when consumers jointly choose quantity and quality, unit values can only be used as proxies for prices because they contain information on both price and quality (Deaton, 1987). This may lead to biases in the estimation of the relevant parameters. Further, endogenous income responses generate additional income effects that can bias the estimates of Marshallian demand elasticities. This is a version of the "profit effect" discussed, for instance, in Singh, Squire and Strauss (1986). Building on the seminal work of Deaton $(1987,1988,1990)$, I develop methods to incorporate income responses and to correct the estimates of consumption responses.

The procedure works as follows. By modeling consumer choices of quantity and quality simultaneously, as in Deaton's work, I extract the right price signals from unit values, expenditures, and quality choices. Then, I use this price information to estimate the response of consumption and wage agricultural income. To do this, I develop a thorough econometric model of agricultural prices, quantities consumed, unit values, and household income.

I estimate the own- and cross-price elasticities as well as the wage-price elasticities using survey data for rural Mexico. It is shown that using unit values instead of prices may indeed lead to inconsistent results, and that the corrections suggested in this paper are empirically important. On the income side, the endogeneity of unit values and measurement error lead to attenuation bias in the estimates of the wage elasticities. On the demand side, the correction for the endogeneity of household agricultural income seems to make a difference in terms of the Marshallian elasticities. These differences originate in the consistent estimation of the expenditure elasticities and in the account of the "profit effect." Finally, by looking WTO reforms are an example. The method proposed here accommodates these cases. 
at different global trade scenarios in agriculture, I show that the evaluation of these trade reforms is very sensitive to the inclusion of both consumption and income effects, as well as to the allowance for consumption and income responses.

The paper is organized as follows. In Section 2, I introduce the econometric model and I provide an overview of the methodology. Here, I discuss the theory that supports my empirical model. The different parts of the model address consumer choices of quality and quantity, wage agricultural income responses, and prices responses to a trade shock. In Section 3, I develop the econometric model of consumption and income responses with many agricultural goods. In section 4, I apply the methods to the Mexican data and I report the results on the demand and wage income price-elasticities. In Section 5, I assess the methodology by simulating welfare impacts under competing empirical models. In Section 6 , I conclude.

\section{The Model}

In most studies of price reforms, such as those summarized in Deaton (1997), the analysis is based on the responses of household consumption. Standard arguments of efficiency, based on price elasticities, and equity, based on expenditure elasticities, are used to characterize optimal taxes or to indicate direction of changes in the structure of taxation. The empirical model of demand developed by Deaton $(1987 ; 1988 ; 1990)$ can be used to estimate income elasticities as well as compensated and uncompensated demand elasticities. This analysis, however, omits important aspects of the effects of any policy, namely the responses of outputs, wages, and household income. To estimate the impacts of the reforms both on the expenditure and income sides, I argue that it is necessary to estimate own- and cross-price elasticities, on the one hand, and wage-price elasticities, on the other. In this section, I explain how to extend Deaton's model to introduce income responses into the demand analysis.

Discussions about the poverty impacts of trade reforms often make the argument that supply responses are critical for the poor. Specifically, WTO reforms on agricultural trade 
are expected to boost production opportunities in rural areas in developing countries. Proponents of this view argue that agricultural trade liberalization will bring about increases in international prices of agricultural goods. Faced with higher permanent prices, households will choose to devote more resources to agricultural production and firms will increase their labor demand in agriculture. This higher demand may involve higher employment in rural farms (for planting, weeding, or harvesting), or it may imply higher labor demand in agricultural services (such as sales of fertilizers and tools and farm maintenance).

How can these effects be estimated? With a household survey database containing information on expenditures and quantities of agricultural goods, a naive model to estimate the responses of agricultural wage income (value of production plus wages) to changes in agricultural prices would be to run a regression of wages on unit values. Let $a_{h c}$ be the agricultural wage income of household $h$ living in region (cluster) $c$. Let $\ln v_{c}^{g}$ be the $\log$ unit values of good $g$ reported by households in cluster $c$. A simple model would be

$$
\ln a_{h c}=\alpha+\gamma^{\prime} \mathbf{m}_{h c}+\sum_{g} \lambda_{g} \ln v_{c}^{g}+u_{h c}
$$

where $\mathbf{m}_{h c}$ is a vector of controls such as gender, age and marital status of the household head, his/her education, household size and demographic composition, and time and regional dummies.

There are three concerns with a regression model such as (1): endogeneity of unit values, bias due to proxy variables, and measurement error. Endogeneity may arise because households simultaneously choose quantity and quality. Therefore, unit values are not a perfect measure of prices. Even when unit values are a good proxy for prices, the model may estimate the vector $\gamma$ consistently, but $\lambda$ inconsistently (i.e., the proxy bias). Measurement error arises if there are inaccurate responses, mainly on quantities consumed. In all these cases, OLS estimation of (1) will lead to inconsistent estimates of the wage agricultural income price-elasticities. The joint estimator developed in this section takes care of all these problems.

In a model with wage and supply responses, there may be additional problems in the 
estimation of own- and cross-price elasticities using the standard empirical models of demand developed by Deaton $(1987 ; 1990)$. Concretely, when a fraction of household income responds to price changes, the elasticities will be inconsistently estimated. To see this, let household preferences over agricultural and non-agricultural goods be defined by a utility function $u_{h}=u_{h}\left(\mathbf{c}_{h}\right)$, where $\mathbf{c}_{h}$ is a vector of consumption. Utility is maximized subject to the budget constraint $\mathbf{p} \mathbf{c}_{h}=x_{h}$. The vector of demand functions is $\mathbf{c}^{h}=\mathbf{c}^{h}\left(\mathbf{p}, x^{h}\right)$.

In a typical model of demand, total expenditure $x_{h}$ is considered exogenous (both economically and statistically). In household production models, instead, at least a part of expenditure can be endogenous. In my model, for example, wage agricultural income depends on the prices of the agricultural goods through changes in demand for labor in agricultural activities. In consequence, a decline, say, in prices has two sources of income effects: the usual income effect, whereby real income increases at constant relative prices, and the change in nominal income caused by the responses of agricultural wage income.

In the development literature, this effect has been labeled "profit effect" in the work of Barnum and Squire (1979) and Singh, Squire and Strauss (1986). In these household production models, a change in prices brings about a change in household profits in agriculture and a change in income. Singh, Squire and Strauss argued that, both in theory and in practice, the profit effect could significantly alter the magnitude, and even the sign, of the uncompensated quantity responses. To see this formally, differentiate the demand of good $c_{1}$, say, with respect to the price $p_{1}$ to get

$$
\frac{\partial c_{h 1}}{\partial p_{1}}=\frac{\partial \widetilde{c}_{h 1}}{\partial p_{1}}-c_{h 1} \frac{\partial c_{h 1}}{\partial x_{h}}+\frac{\partial c_{h 1}}{\partial x_{h}} \frac{\partial x_{h}}{\partial p_{1}},
$$

where $\partial \widetilde{c}_{h 1} / \partial p_{1}$ is the standard compensated demand change and $-c_{h 1} \partial c_{h 1} / \partial x_{h}$ is the standard income effect (from the Slutsky equation). The last term measures the additional income effect caused by my version of the profit effect, i.e., the response of household total expenditure through the changes in agricultural wages. Figure 1 provides an intuition. The initial price vector is $\mathbf{p}^{0}$; at these prices, the consumer chooses the bundle $\mathbf{c}^{0}$ of goods. Let's assume that the price of good 1 (with quantities measured on the horizontal axis) declines and that wage agricultural income $a_{h}$ is negatively associated with this price. This means 
Figure 1

The Profit Effect and the Marshallian Demand Elasticities

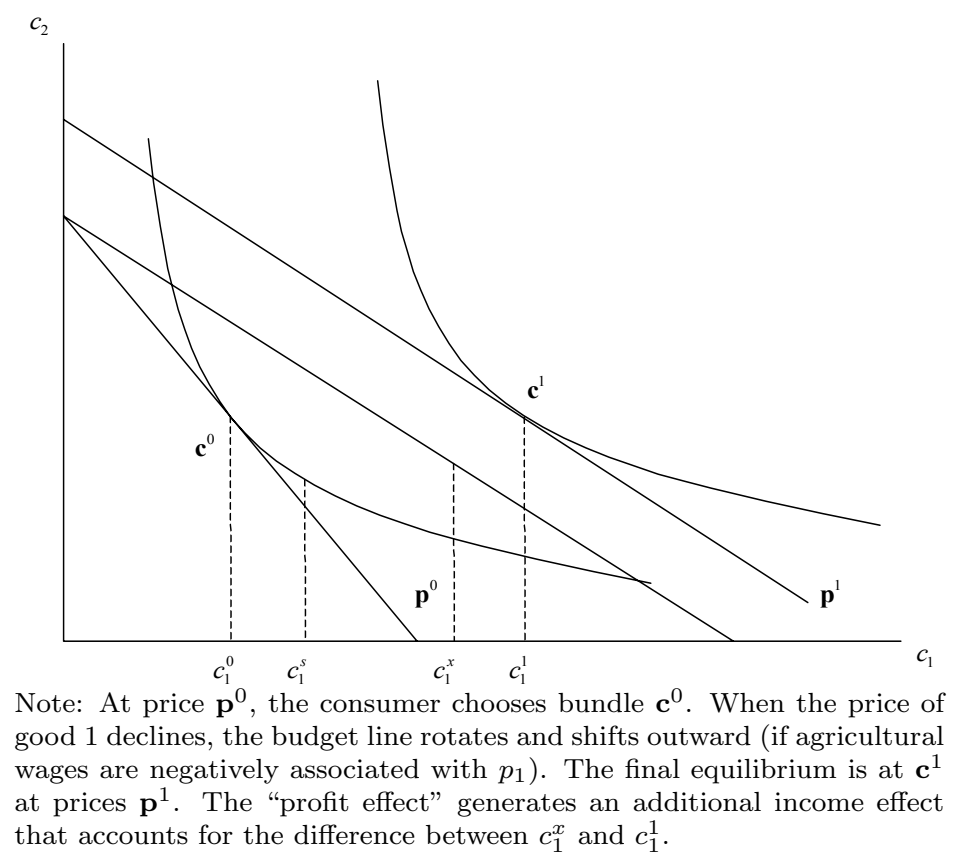

that when $p_{1}$ declines, the budget line first rotates (with nominal income held constant) and then shifts, when $a_{h}$ increases. The final equilibrium at the price vector $\mathbf{p}^{1}$ is at $\mathbf{c}^{1}$. The substitution effect is the movement from $c_{1}^{0}$ to $c_{1}^{s}$. The standard income effect is the movement from $c_{1}^{s}$ to $c_{1}^{x}$ and the remaining units, from $c_{1}^{x}$ to $c_{1}^{1}$, measure the additional income effect caused by my version of the profit effect, i.e., the response of household total expenditure through the changes in agricultural wages. In the case depicted in Figure 1, the consumption of good 1 increases with lower prices. But it is easy to build cases in which consumption actually declines when prices are lower, even for a normal good. The joint estimator developed next incorporates these additional income effects.

\subsection{A simplified Model}

The method proposed in this paper combines a model such as (1), with true unobservable prices instead of unit values as regressors, with the model of demand and quality shading developed by Deaton $(1987,1988,1990)$. In order to introduce the method, I begin by setting 
up a simplified version of the model with only one good. ${ }^{2}$ It is convenient to describe the model in blocks, first discussing households as consumers and then households as income earners.

\subsubsection{Consumers}

A useful model of consumer choice to estimate demand parameters from household data has been developed by Angus Deaton in his original contributions (Deaton, 1987; Deaton, 1990). Since my major extension in this paper is the modeling of households as income earners, here I adopt this model. The demand for the good is modeled with an equation characterizing the budget share $s_{h c}$ spent by household $h$ in cluster $c$

$$
s_{h c}=\alpha_{0}+\beta_{0} \ln x_{h c}+\gamma_{0}^{\prime} \mathbf{z}_{h c}+\theta \ln \pi_{c}+f_{c}+u_{h c}^{0}
$$

where $x_{h c}$ is total expenditure, $\mathbf{z}_{h c}$ are household demographic characteristics, such as number of members and demographic composition. $\pi_{c}$ is a price level that is assumed to be the same for all households in cluster $c$; this price is unobservable. $f_{c}$ is a cluster fixed effect and $u_{h c}^{0}$ is a standard error term, with zero mean (for a large number of households in each cluster) and variance $\sigma^{00}$.

Prices $\pi_{c}$ are not observable to the econometrician, but unit values are. However, unit values are not the same as prices because they are part price and part quality. In fact, changes in prices and in total expenditure will cause consumers to respond partly by modifying quantities and partly by modifying quality. This endogeneity of unit values can be solved by modeling unit values explicitly. Deaton assumes that

$$
\ln v_{h c}=\alpha_{1}+\beta_{1} \ln x_{h c}+\gamma_{1}^{\prime} \mathbf{z}_{h c}+\psi \ln \pi_{c}+u_{h c}^{1} .
$$

Here, unit values $v_{h c}$ are affected by prices and by household expenditure $x_{h c}$. The parameter $\psi$ captures the shading of quality to price changes, and the parameter $\beta_{1}$ is called the "quality

\footnotetext{
${ }^{2}$ I describe this artificial model just to provide an intuition for the more difficult formulas of the full model of section 3. No attempt to generality or general equilibrium is pursued here.
} 
elasticity" or the "expenditure elasticity of quality"; $\beta_{1}$ would be zero if there were no quality shading, in which case $\psi=1$. Demographics $\mathbf{z}_{h c}$ determine unit values, too. The error term $u_{h c}^{1}$ has mean zero (for a large number of $h$ in cluster $c$ ) and variance $\sigma^{11}$.

Equations (2) and (3) characterize Deaton's demand model. It is well-known that this model can only identify the ratio $\theta / \psi$. To identify these parameters separately, Deaton imposes a group separability restriction on preferences that provides a link (i.e., a theoretical restriction) between the response of quality and quantity to income and prices. Deaton (1988) shows that (see also Appendix 1)

$$
\text { (4) } \psi=1+\beta_{1} \frac{\epsilon_{p}}{\epsilon_{x}}
$$

where $\epsilon_{p}$ is the price elasticity of quantity with respect to price $\pi$ and $\epsilon_{x}$ is the total expenditure elasticity of the group. To derive this restriction, Deaton assumes that more expensive goods are higher quality goods. His definition implies that total expenditure is the product of price, quantity and quality so that unit values are the product of price and quality. In consequence, the response of unit values to prices, $\psi$, differs from one by the quality shading term $\left(\epsilon_{p} \beta_{1} / \epsilon_{x}\right)$, that depends on the quality elasticity, $\beta_{1}$, the price elasticity $\epsilon_{p}$, and the income elasticity, $\epsilon_{x}$. If $\beta_{1}=0$ or $\epsilon_{p}=0$, then there is no quality shading and $\psi=1$. When there is quality shading to prices, $\psi<1$.

Note that equations (2) and (3) are a representation of the regression functions of budget shares and unit values. Although it is not possible to be sure that these functional forms are derived from some preferences (and thus that the structural preference parameters are identified), it is enough for (trade) policy evaluation to know the demand parameters, like price elasticities, and these are identified under the linearity assumption. There are two unresolved problems with this linearity assumption: As Deaton (1990) pointed out, linearity may cause a misspecification of the budget share regression function when zero observations are included; as pointed out by Crawford, Laisney, and Preston (2003), the linearity of budget shares may be inconsistent with the separable representation of preferences. However, as it will be evident in the estimation strategy, this linearity is needed to "difference out" the unobserved prices in the model. 


\subsubsection{Wage Agricultural Income}

The demand model in equations (2) and (3) and the separability restriction can be used to extract true price signals from unit values. I use this price information to estimate the endogenous determination of household wage agricultural income, $a_{h c}$, which is the main extension of this paper. Before laying out the empirical model, I want to begin with a theoretical discussion of the type of impacts that I want to estimate, that is, household responses to trade policy. The emphasis on trade reforms is because, as I explain below, my analysis relies on exogenous prices and tradable goods satisfy this requirement. ${ }^{3}$ As an example of such trade reforms, consider the current Doha negotiations under WTO on production and export subsidies as well as trade protection in agriculture. If these barriers were eliminated, international prices would increase, thus affecting outcomes and behavior in rural households in developing countries. In equilibrium, changes in tradable product prices (corn, for instance) will bring about changes in factor prices (wages), household income, and consumption choices (both of quality and quantity). In this paper, I am interested in agricultural production and wage responses.

In rural areas, household members may work in local farms in exchange for a wage, may work on their own farms, or may work in agricultural activities (provision of services, sales of inputs). Income derived from all these activities is denoted by $a_{h}$ and is called agricultural wage income. Wages or other incomes earned in non-agricultural activities are denoted with $i_{h}$. For simplicity, I assume that this income $i_{h}$ is exogenous. Thus, total household income $x_{h}$ is given by

$$
x_{h}=a_{h}+i_{h} .
$$

My aim here is to discuss how $a_{h}$ is affected by a change in agricultural prices. I assume that there are two types of agricultural activities: $a g^{1}$ comprises cropping activities; $a g^{2}$ are, instead, livestock activities, such as animal husbandry or production of dairy products.

\footnotetext{
${ }^{3}$ In principle, my model can be used to estimate more general price reforms provided these reforms affect tradable goods. In contrast, price reforms affecting non-tradable goods (such as privatization of services, for example) cannot be studied with this procedure.
} 
There are three differentiated labor inputs in rural areas: agricultural labor of type 1 (with total supply $L^{1}$ ), agricultural labor of type 2 (with supply $L^{2}$ ), and mobile labor (with supply $\left.L^{m}\right) . L^{1}$ is specific to agricultural activities 1 . This includes labor for planting, weeding, harvesting, etc. I assume there are many agricultural activities $a g_{g}^{1}$ in sector 1 ; the common feature of activities $g$ is that they use $L^{1}$ intensively. For instance, one activity can be growing corn and another, growing fruits \& vegetables. Both activities require workers with agrarian skills. Similarly, there may be several activities $k$ in sector 2 , denoted $a g_{k}^{2}$. Animal husbandry, dairy production, veterinary services, etc. are examples. Activities 1 and 2 share mobile labor $L^{m}$. Notice that since labor types $L^{1}, L^{2}$, and $L^{m}$ are differentiated inputs, they can earn a different wage.

The production function of activity $g$ (corn, for instance) in sector 1 (agrarian) is $f_{g}^{1}=$ $f_{g}^{1}\left(l_{g}^{1}, l_{g}^{m}\right)$, where $l_{g}^{1}$ is employment of specific factor 1 , and $l_{g}^{m}$ is employment of mobile labor. There may be other factors used in the production of $g$ (such as land or capital), but I omit this discussion for simplicity.

To capture the fact that there are significant regional disparities in rural Mexico (Hanson, 1997; Robertson, 2000) and in order to exploit the regional disparities in the unit values from the household surveys as identifying variation, I assume that there is a certain degree of labor immobility across regions. This is possible if there are relocation costs of rural labor. In the end, thus, labor supply in region $c$ is given by $L_{c}^{1}, L_{c}^{2}$, and $L_{c}^{m}$, and agricultural wages will vary by region.

Producers of agricultural activities $g$ in locality $c$ face exogenous prices $\pi_{c g}$, which depend on international prices and domestic conditions such as transport or transaction costs (see below). Profit maximization leads to labor demand functions

$$
l_{c g}^{1}=l_{c g}^{1}\left(w_{c}^{1}, w_{c}^{m}, \pi_{c 1}, \ldots, \pi_{c g}, \ldots, \pi_{c M}\right)
$$

where $w_{c}^{1}$ is the agricultural wage in sector $1, w_{c}^{m}$ is the agricultural wage of mobile labor, and the $\pi_{c g}$ are agricultural price products (corn, fruits \& vegetables, wheat, dairy). Labor market clearing conditions in locality $c$ (which require the equality of total labor demand 
and supply for each type of labor) imply that agricultural wages are given by

$$
w_{c}^{r}=w_{c}^{r}\left(\pi_{c 1}, \ldots, \pi_{c g}, \ldots, \pi_{c M} ; \chi\right), \quad r=1,2, m
$$

where the vector $\chi$ captures non-price determinants of wages (such as individual characteristics). These equations show how the agricultural wage income of the household (which is a mixture of $w_{c}^{1}, w_{c}^{2}$ and $w_{c}^{m}$ ) depends on the prices of agricultural goods, $\pi$. Notice that, in the Mexican data used below, households report agricultural wages without identifying the agricultural activities on which wages are earned (type 1, type 2 or mobile). This means that I can estimate only the average response of agricultural income, which is a weighted average of the responses of $w^{1}, w^{2}$ and $w^{m}$. That is, since $\ln a=\mu^{1} \ln w^{1}+\mu^{2} \ln w^{2}+\mu^{m} \ln w^{m}$, it follows that

$$
\lambda_{g}=\mu^{1} \frac{\partial \ln w^{1}}{\partial \ln \pi_{g}}+\mu^{2} \frac{\partial \ln w^{2}}{\partial \ln \pi_{g}}+\mu^{m} \frac{\partial \ln w^{m}}{\partial \ln \pi_{g}},
$$

where $\mu^{r}$ are weights given by the share of each type of labor on total labor supply. This equation shows that the average response of agricultural wage income can be positive or negative depending upon the relative importance of the different types of labor and the differential responses of $w^{1}, w^{2}$ and $w^{m}$ to prices.

Figure 2 plots the equilibrium in a standard specific factor framework. The horizontal size of the box measures $L^{m}$, the total labor supply of mobile labor. The curve labeled $l^{1}$ is the value of the marginal product of mobile labor in agricultural activities of type 1 . As drawn, there are two such activities, say corn $(\operatorname{good} g)$ and fruits \& vegetables (good $\left.g^{\prime}\right)$. The curve $l^{2}$ represents the demand for mobile labor in agricultural activities of type 2. For simplicity, there is only one activity in sector 2, namely dairy.

In the Figure, I have purposely assumed a much larger demand for labor in activities 1 than in activities 2. Accordingly, an increase in prices $\pi_{g}$ or $\pi_{g^{\prime}}$ (the prices of corn or of fruits \& vegetables) would shift $l^{1}$ up, causing $w^{m}$ to increase. In addition, while $w^{1}$ would increase as well, $w^{2}$ would decline. In contrast, an increase in $\pi_{k}$ (the price of dairy) would cause $w^{m}$ and $w^{2}$ to increase, but $w^{1}$ to decline. In consequence, the situation plotted in 
Figure 2

Rural Agricultural Labor Markets

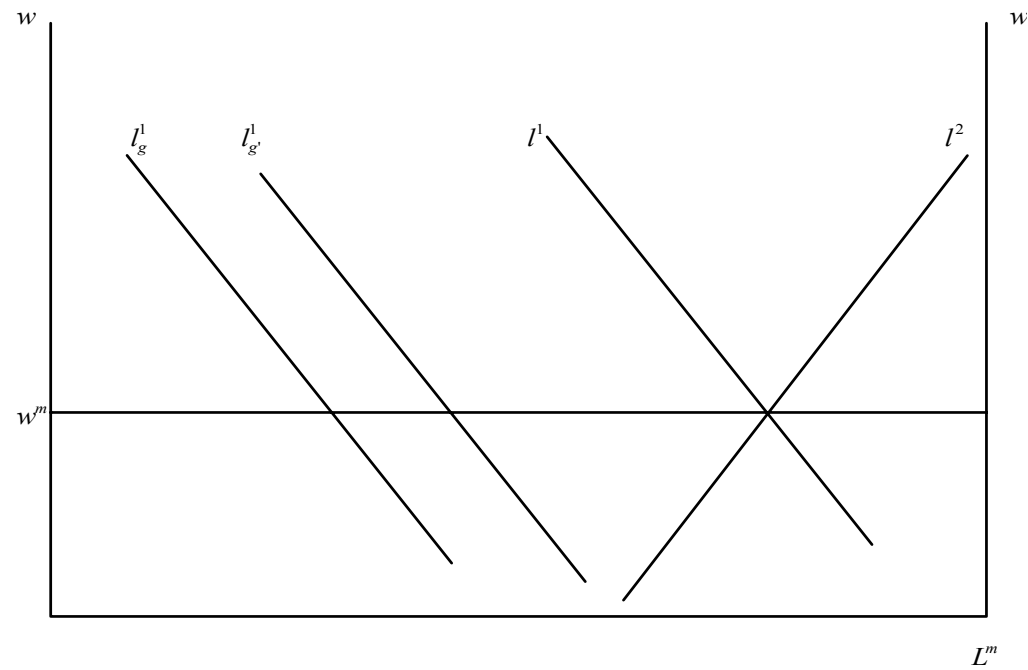

Note: The length of the horizontal box is the supply of mobile labor $L^{m}$; its wage is $w^{m}$. The curves $l_{g}^{1}$ and $l_{g^{\prime}}^{1}$ represent the labor demand in activities of type 1 (which use specific labor $L^{1}$ ). The total demand of this specific labor is $l^{1}$. The total labor demand in activities of type 2 is $l^{2}$.

Figure 2 suggests that increases in the prices of corn or fruits \& vegetables would most likely cause average wage income to increase, but increases in the price of dairy would most likely cause wage income to decline. It is clear that, theoretically, anything can happen and that wage income can increase or decrease. This is, in the end, an empirical question and I shall give examples of the working of the model in section 4 .

Turning to the econometric specification (and remembering that I am setting up a simple model with one good for exposition purposes), I can redefine (1) as

$$
\ln a_{h c}=\alpha_{2}+\gamma_{2}^{\prime} \mathbf{m}_{h c}+\lambda \ln \pi_{c}+u_{h c}^{2}
$$

where $\mathbf{m}_{h c}$ are household characteristics that affect wage agricultural income. Some elements of $\mathbf{m}_{h c}$, such as education, are different from the determinants of the budget shares and unit values. $u_{h c}^{2}$ is a standard error term. The coefficient $\lambda$ measures the wage-price elasticity. ${ }^{4}$

\footnotetext{
${ }^{4}$ While consumer prices are relevant in equations (2) and (3), producer prices are more important in determining wages. Since information on unit values in production is not available, I need to rely on consumer prices and unit values on consumption as a source of variation for producer prices. This is a common problem in the literature (see Edmonds and Pavcnik, 2005).
} 
The addition of equation (6) to the demand model in (2) and (3) allows me to introduce income responses into the model.

A critical identifying assumption of both Deaton's model and my extension in this paper is that prices vary geographically. This strategy raises a number of concerns. First, the fact that prices are geographically different has to be reconciled with the fact that tradable goods face exogenous prices in international markets. Second, once prices are allowed to differ regionally, the fact that wages can adjust to the change in the price of a tradable good while the prices of the other tradable goods will not adjust needs to be explained. ${ }^{5}$

For a small open economy, the prices of tradable goods are given in international markets and can thus be considered exogenous in the empirical analysis. In my model, however, prices of tradable goods are allowed to be different in different regions. This assumption is supported by models of imperfect price transmission, which imply that changes in international prices are not transmitted one to one to the local economy and that this pattern of imperfect pass-through is likely to be geographically different within a country (Goldberg and Knetter, 1997).

These regional differences can arise from several reasons. The first obvious candidate is transportation costs. In Mexico, for instance, most trade takes place with the U.S. and regions further away from the border experience different prices from regions closer to the border (Nicita, 2006). Another explanation leans on differences in the cost of doing business that affect the distribution costs of trade intermediaries and retailers. These costs can include the costs of local regulations (packaging of agricultural products, disease control, environmental care), municipal taxes and fees (sales permits, registration of businesses), rental prices, electricity, telecommunications, and informal costs like bribes. All these costs can be broadly thought of as transaction costs that can affect the business environment differentially in different regions, thus leading to different local prices.

\footnotetext{
${ }^{5}$ Notice that the prices of nontradable goods will indeed adjust. Unfortunately, I will not be able to capture these general equilibrium effects in this paper. See Porto (2006) for an attempt to do this using time series of prices in Argentina.
} 
To be more precise, I write the price of good $g$ in cluster $c$ as

$$
\pi_{c g}=\pi_{g}^{*}\left(1+\mu_{c g}\right)
$$

where $\pi_{g}^{*}$ is the international price and $\mu_{c g}$ captures the wedge between the international price and the local, regional price. The key assumption here are that $\pi_{g}^{*}$ is given and that the wedge accruing to good $g$ does not depend on the prices of other tradable goods. In other words, $\mu_{c g}$ has to be exogenous to $\pi_{k}^{*}$, for $k \neq g$. This will hold if, for instance, transportation costs depend mostly on distance (road tolls), capital costs (truck and road maintenance) and fuel costs, which can be safely assumed to be exogenous to the international prices of agricultural goods. Also, I need local taxes and regulations, as well as transaction costs, and the business and investment climate to be exogenous to agricultural international prices, a reasonable assumption. ${ }^{6}$ Finally, notice that international prices need to be exogenous to the households under study, but they need not be exogenous to the trade reforms. In a global scenario, a trade reform in good $g$ can affect the international prices of goods $k$. The important point here is that these changes are exogenous.

\subsubsection{Estimation}

If prices $\pi_{c}$ were observed, it would be straightforward to estimate a model characterized by (2) and (6). ${ }^{7}$ When prices $\pi_{c}$ are not observed, a plausible identification assumption is that every household in cluster $c$ faces the same prices. Under this assumption, Deaton (1988) suggested a useful two-stage strategy. In the first stage, unobserved prices are controlled for with cluster dummies (which will absorb any fixed effects as well). In the second stage, the elasticities are estimated by using the information on prices contained in the residuals from the first stage. Details follow.

In the first stage, I recover $\beta_{0}, \gamma_{0}, \beta_{1}, \gamma_{1}$ and $\gamma_{2}$ by consistently estimating the

\footnotetext{
${ }^{6}$ Inasmuch as there is a labor component to transportation and transaction costs, then the wedges $\mu_{c g}$ will be partly endogenous. However, there is evidence to believe that, in developing countries, the labor component of transport and transaction costs is fairly small to safely assume exogenous prices of traded goods.

${ }^{7}$ When prices are observed, the unit value equation is not needed.
} 
model, after demeaning all variables $\left(s_{h c}, \ln v_{h c}, \ln a_{h c}, \ln x_{h c}, \mathbf{z}_{h c}\right.$, and $\left.\mathbf{m}_{h c}\right)$ from cluster means. Consistency may be achieved with OLS, if expenditures are considered statistically exogenous, or with IV. I elaborate more on this when I discuss the full model in section 3. With estimates $\widehat{\beta}_{0}, \widehat{\gamma}_{0}, \widehat{\beta}_{1}, \widehat{\gamma}_{1}$ and $\widehat{\gamma}_{2}$, I construct three variables by subtracting the explained part of the model from the dependent variables in (2), (3) and (6). I get

$$
\begin{aligned}
& \text { (7) } \widehat{y}_{h c}^{0}=s_{h c}-\widehat{\beta}_{0} \ln x_{h c}-\widehat{\gamma}_{0}^{\prime} \mathbf{z}_{h c}, \\
& \text { (8) } \widehat{y}_{h c}^{1}=\ln v_{h c}-\widehat{\beta}_{1} \ln x_{h c}-\widehat{\gamma}_{1}^{\prime} \mathbf{z}_{h c} \\
& \text { (9) } \widehat{y}_{h c}^{2}=\ln a_{h c}-\widehat{\gamma}_{2}^{\prime} \mathbf{m}_{h c} .
\end{aligned}
$$

Averaging (7), (8) and (9) at the cluster level, it follows that

$$
\widehat{y}_{c}^{0} \stackrel{p}{\longrightarrow} \alpha_{0}+\theta \ln \pi_{c}+f_{c}+u_{c}^{0}
$$

$$
\begin{aligned}
& \widehat{y}_{c}^{1} \stackrel{p}{\longrightarrow} \alpha_{1}+\psi \ln \pi_{c}+u_{c}^{1}, \\
& \widehat{y}_{c}^{2} \stackrel{p}{\longrightarrow} \alpha_{2}+\lambda \ln \pi_{c}+u_{c}^{2},
\end{aligned}
$$

where $u_{c}^{0}, u_{c}^{1}$, and $u_{c}^{2}$ are average error terms in cluster $c$ (these averages would be zero for a sufficiently large number of households per cluster).

Notice that the "residuals" $\widehat{y}_{c}^{0}, \widehat{y}_{c}^{1}$, and $\widehat{y}_{c}^{2}$ contain the parameters of interest, $\theta$, $\psi$, and $\lambda$, and unobserved prices. The slope of a regression of $\widehat{y}_{c}^{0}$ on $\widehat{y}_{c}^{1}$, taking into account the covariance of mean cluster errors, is given by

$$
\widehat{\phi}_{1}=\frac{\widehat{\operatorname{cov}}\left(\widehat{y}_{c}^{0}, \widehat{y}_{c}^{1}\right)-\frac{\widehat{\sigma}^{01}}{n_{c}}}{\widehat{\operatorname{var}}\left(\widehat{y}_{c}^{1}\right)-\frac{\widehat{\sigma^{11}}}{n_{c}}}=\frac{\widehat{\theta}}{\widehat{\psi}},
$$

where $n_{c}$ is the (common) number of observations (households) in a cluster $c, \widehat{\sigma}^{01}$ is the estimated covariance between the residuals in the budget share equations and unit value equations, and $\widehat{\sigma}^{11}$ is the estimated variance of the residuals of the unit value equation. ${ }^{8}$

\footnotetext{
${ }^{8}$ Deaton (1987) discusses how to amend the formulas for the cases where the number of households is different across clusters and where not every household in a cluster reports both budget shares and unit
} 
Similarly, the slope of a regression of $\widehat{y}_{c}^{0}$ on $\widehat{y}_{c}^{2}$ is given by

$$
\widehat{\phi}_{2}=\frac{\widehat{\operatorname{cov}}\left(\widehat{y}_{c}^{0}, \widehat{y}_{c}^{2}\right)-\frac{\widehat{\sigma}^{02}}{n_{c}}}{\widehat{\operatorname{var}}\left(\widehat{y}_{c}^{2}\right)-\frac{\widehat{\sigma}^{22}}{n_{c}}}=\frac{\widehat{\theta}}{\widehat{\lambda}},
$$

where $\widehat{\sigma}^{02}$ is the estimated covariance between the residual in the equation for budget shares and the equation for wage agricultural income and $\widehat{\sigma}^{22}$ is the variance of the residuals in the wage agricultural income equation.

Without further restrictions on the parameters of the model, it is not possible to separate $\widehat{\theta}, \widehat{\psi}$ and $\widehat{\lambda}$ from the ratios $\widehat{\phi}_{1}$ and $\widehat{\phi}_{2}$. As explained above, the identification restriction is equation (4), which is derived from Deaton model of quality with group-separable preferences. This restriction, however, has to be amended to take into account the wage responses of the household and the "profit effect." In Appendix 1, I relate the quantities $\epsilon_{p}$ and $\epsilon_{x}$ to the estimable parameters to derive the empirical restriction that identifies the model

$$
\psi=1+\beta_{1} \frac{\frac{\theta}{s}+b_{a} \lambda-\psi}{\frac{\beta_{0}}{s}+1-\beta_{1}},
$$

where $b_{a}$ is the average share of wage agricultural income in total expenditure, and $s$ is the average budget share. The empirical version of (13) can be combined with the estimates of $\widehat{\phi}_{1}$ and $\widehat{\phi}_{2}$ to solve for $\widehat{\theta}, \widehat{\psi}$ and $\widehat{\lambda}$. A generalization to the case of many goods follows.

\section{The Full Model}

In this section, I derive the formulas needed to implement the full model, with many agricultural goods, cross-price elasticities, and several agricultural wage price-elasticities. With $G$ goods, the budget share spent on good $g$ by household $h$ (in cluster $c$ ) is

$$
s_{h c}^{g}=\alpha_{0}^{g}+\beta_{0}^{g} \ln x_{h c}+\gamma_{0}^{g \prime} \mathbf{z}_{h c}+\sum_{k \in G} \theta_{g k} \ln \pi_{c}^{k}+f_{c}^{g}+u_{h c}^{g 0},
$$

values. 
where $\ln \pi_{c}^{k}$ is the (log) price of good $k$ in cluster $c$. As before, $f_{c}^{g}$ is a fixed effect at the cluster level and $u_{h c}^{g 0}$ is the error term, with mean zero and variance $\sigma_{00}^{g} \cdot{ }^{9}$

The unit value equation for good $g$ is

$$
\ln v_{h c}^{g}=\alpha_{1}^{g}+\beta_{1}^{g} \ln x_{h c}+\gamma_{1}^{g \prime} \mathbf{z}_{h c}+\sum_{k \in G} \psi_{g k} \ln \pi_{c}^{k}+u_{h c}^{g 1}
$$

Here, the "quality elasticity" for good $g$ is $\beta_{1}^{g}$. The error term $u_{h c}^{g 1}$ has zero mean and variance $\sigma_{11}^{g}$. This is just the generalization of equation (3).

There are $G$ equations (14) and (15); instead, there is only one agricultural wage income equation

$$
\ln a_{h c}=\alpha_{2}+\gamma_{2}^{\prime} \mathbf{m}_{h c}+\sum_{k \in G} \lambda_{k} \ln \pi_{c}^{k}+u_{h c}^{2}
$$

where $u_{h c}^{2}$ is an error term.

As in the simplified model, estimation proceeds in two stages. In the first stage, I demean budget shares, log unit values and log agricultural income to eliminate prices and cluster fixed effects. In principle, there is no problem with the consistent estimation of these parameters if the regressors are exogenous, as in Deaton (1990). Here, however, I am introducing an agricultural wage income equation and agricultural income may be correlated with total expenditure. This means that the model will not be identified if there is correlation between the errors of the share or unit value equations with the error of the agricultural wage income equation.

If I assume that this correlation is absent, then the model is triangular and I can estimate it consistently using OLS equation by equation. This assumption is not necessary. It is possible to allow for correlation between $u_{h c}^{2}, u_{h c}^{1}$ and $u_{h c}^{0}$ and estimate consistently the parameters of the demeaned model using instruments in the share and unit value equations. In particular, since the set of explanatory variables in $\mathbf{m}_{h c}$ is different from the set of explanatory variables in $\mathbf{z}_{h c}$, I can use the variables that are in $\mathbf{m}$ but not in $\mathbf{z}$ as instruments.

\footnotetext{
${ }^{9}$ Notice that this is not a AIDS model of demand (Deaton and Muellbauer, 1980) but only a linear approximation to it.
} 
These exclusion restrictions allow me to fully identify the parameters of the first stage. The parameters of the agricultural wage income equation are identified provided $\mathbf{m}$ is exogenous. ${ }^{10}$

In the second stage, I subtract the explained part of the model from each of the dependent variables, and I compute their averages by clusters. It follows that

$$
\begin{aligned}
& \widehat{y}_{c g}^{0} \stackrel{p}{\longrightarrow} \alpha_{0}^{g}+\sum_{k \in G} \theta_{g k} \ln \pi_{c}^{k}+f_{c}^{g}+u_{c g}^{0}, \\
& \widehat{y}_{c g}^{1} \stackrel{p}{\longrightarrow} \alpha_{1}^{g}+\sum_{k \in G} \psi_{g k} \ln \pi_{c}^{k}+u_{c g}^{1}, \\
& \widehat{y}_{c}^{2} \stackrel{p}{\longrightarrow} \alpha_{2}+\sum_{k \in G} \lambda_{k} \ln \pi_{c}^{k}+u_{c}^{2}
\end{aligned}
$$

where $u_{c g}^{0}, u_{c g}^{1}$, and $u_{c}^{2}$ are average error terms in cluster $c$.

Whereas in the simplified model I was interested in three parameters, $\psi, \theta$ and $\lambda$, here I need to estimate two matrices and one vector of parameters. The matrices are $\boldsymbol{\Psi}$ and $\Theta$, with gth row denoted by $\psi_{\mathbf{g}}=\left(\psi_{g 1}, \ldots, \psi_{g g}, \ldots, \psi_{g G}\right)$ and $\theta_{\mathbf{g}}=\left(\theta_{g 1}, \ldots, \theta_{g g}, \ldots, \theta_{g G}\right)$, respectively. The vector of wage elasticities is $\lambda=\left(\lambda_{1}, \ldots, \lambda_{G}\right)^{\prime}$.

To solve for the matrices of parameters, $\boldsymbol{\Theta}, \boldsymbol{\Psi}$, and $\lambda$, I need to manipulate the model and introduce some new notation. Let $\mathbf{p}_{c}$ be a $G \times 1$ vector of the logarithm of (unobserved) prices in cluster $c$. Stacking the vectors $\mathbf{p}_{c}^{\prime}$ for all clusters, I get a $C \times G$ matrix $\mathbf{P}$ of prices. Next, I stack observations on average unit values for good $g$, (18), into a $C \times 1$ vector $\widehat{\mathbf{y}}_{g}^{1}=\mathbf{1}_{C} \alpha_{1}^{g}+\mathbf{P} \psi_{g}^{\prime}+\mathbf{u}_{g}^{1}$, where $\mathbf{1}_{C}$ is a $C \times 1$ vector of ones, $\psi_{g}$ is the $g$ th row of matrix $\boldsymbol{\Psi}$ and $\mathbf{u}_{g}^{1}$ is a vector of residuals. It follows that $\operatorname{cov}\left(\widehat{\mathbf{y}}_{g}^{1 \prime}, \widehat{\mathbf{y}}_{k}^{1}\right)=\psi_{g}^{\prime} \boldsymbol{\Pi} \psi_{k}+E\left[\mathbf{u}_{g}^{1 \prime} \mathbf{u}_{k}^{1}\right]$, where $\boldsymbol{\Pi}$ is the variance-covariance matrix of the vector of good prices (across clusters). Thus, I can construct a $G \times G$ matrix $\mathbf{V}_{1}$ with element $g k$ given $\operatorname{cov}\left(\widehat{\mathbf{y}}_{g}^{1 \prime}, \widehat{\mathbf{y}}_{k}^{1}\right)$

$$
\mathrm{V}_{1}=\Psi \Pi \Psi^{\prime}+\Omega_{11}
$$

where $\boldsymbol{\Omega}_{11}$ is the matrix with $g k$ element $E\left[\mathbf{u}_{g}^{1 /} \mathbf{u}_{k}^{1}\right]$.

Following the same procedure, I generate the vector $\widehat{\mathbf{y}}_{g}^{0}$ by stacking the estimated average

\footnotetext{
${ }^{10}$ Notice that the model is recursive: since the agricultural wage income does not depend on total household expenditure, the wage equation can be estimated by OLS.
} 
budget shares spent on good $g$, equation (17), by clusters. This vector is $\widehat{\mathbf{y}}_{g}^{0}=\mathbf{1}_{C} \alpha_{0}^{g}+\mathbf{P} \theta_{g}^{\prime}+$ $\mathbf{f}^{c}+\mathbf{u}_{g}^{0}$, where $\theta_{g}$ is the $g$ th row of matrix $\boldsymbol{\Theta}$, and $\mathbf{u}_{g}^{0}$ is a vector of residuals. I then build a $G \times G$ matrix $\mathbf{V}_{10}$

(21) $\mathbf{V}_{10}=\Psi \Pi \Theta^{\prime}+\Omega_{10}$,

where $\boldsymbol{\Omega}_{10}$ is the matrix with $g k$ element $E\left[\mathbf{u}_{g}^{1 /} \mathbf{u}_{k}^{0}\right]$.

So far, I have shown how estimation of the model of demand delivers algebraic expressions involving the unknown matrices $\boldsymbol{\Theta}$ and $\boldsymbol{\Psi}$; these are equations (20) and (21). These equations can be combined to express one of these matrices as a function of the other. For instance, by defining a matrix $\mathbf{B}=\left[\mathbf{V}_{1}-\Omega_{11}\right]^{-1}\left[\mathbf{V}_{10}-\Omega_{10}\right]$, it follows that

(22) $\mathbf{B}^{\prime} \boldsymbol{\Psi}=\boldsymbol{\Theta}$.

This expression has an interpretation in terms of OLS regression coefficients - corrected for measurement errors - among the average cluster residuals of the unit value and budget share equations for the different goods.

The next step is to develop similar formulas involving the vector $\lambda$ of wage agricultural income price elasticities. One option is to combine the agricultural income equation with the unit value equations. I define the agricultural income equation for cluster $c$ as a stacked vector $\widehat{\mathbf{y}}^{2}=\mathbf{1}_{C} \alpha_{2}+\mathbf{P} \lambda+\mathbf{u}^{2}$, so that I can find the covariance between $\widehat{\mathbf{y}}^{2}$ and $\widehat{\mathbf{y}}_{g}^{1}$ and define a $G \times 1$ vector $\mathbf{v}_{21}$

$$
\mathbf{v}_{21}=\Psi \Pi \lambda+\omega_{21}
$$

where $\omega_{21}$ is a vector with $g$ element $E\left[\mathbf{u}^{2 \prime} \mathbf{u}_{g}^{1}\right]$. Next, I define a $1 \times G$ vector $\mathbf{B}_{1}=$ $\left[\mathbf{v}_{21}-\omega_{21}\right]^{\prime}\left[\mathbf{V}_{1}-\Omega_{11}\right]^{-1}$, so that

$$
\mathbf{B}_{1}=\lambda^{\prime} \Psi^{-1}
$$

This relationship can also be interpreted as OLS slopes (corrected for measurement error). 
To complete the model and solve for the parameters of interest (i.e., the price elasticities), I need to extend the quality model to many goods. In Appendix 1, I show that the generalization of equation (13) is given by

$$
\psi_{g k}=\delta_{g k}+\frac{\beta_{1}^{g}}{\beta_{0}^{g}+s_{g}\left(1-\beta_{1}^{g}\right)}\left[\theta_{g k}+s_{g} b_{a} \lambda_{k}-s_{g} \psi_{g k}\right]
$$

where $\delta_{g k}$ is the Kronecker delta. Defining a vector $\xi$ with element $\beta_{1}^{g} /\left(\beta_{0}^{g}+s_{g}\left(1-\beta_{1}^{g}\right)\right)$ for good $g$, and a vector $\mathbf{s}$ of average budget shares, I can write

$$
\mathbf{\Psi}=\mathbf{I}+D(\xi) \boldsymbol{\Theta}+b_{a} D(\xi) D(\mathbf{s}) \mathbf{1}_{G} \otimes \lambda^{\prime}-D(\xi) D(\mathbf{s}) \mathbf{\Psi}
$$

where $D(\xi)$ and $D(\mathbf{s})$ are matrices with the elements of vectors $\xi$ and $\mathbf{s}$ on the diagonal (and zero off-diagonal elements), and $\mathbf{1}_{G}$ is a $G \times 1$ vector of ones. The symbol $\otimes$ is the Kronecker product.

These are all the steps needed to close the model. The mechanics of the solution involves using (22), (24) and (26) to solve for the matrices $\boldsymbol{\Theta}$ and $\boldsymbol{\Psi}$, and the vector $\lambda$. Replacing (22) in (26), I get

$$
\widehat{\mathbf{\Psi}}=\left[\mathbf{I}-D(\xi) \mathbf{B}^{\prime}-b_{a} D(\xi) D(\mathbf{s}) \mathbf{1}_{G} \otimes \mathbf{B}_{1}+D(\xi) D(\mathbf{s})\right]^{-1} .
$$

This matrix is a function of the data. Plugging this into (22) and (24), I solve for $\widehat{\boldsymbol{\Theta}}=\mathbf{B}^{\prime} \widehat{\mathbf{\Psi}}$ and for $\widehat{\lambda}^{\prime}=\mathbf{B}_{1} \widehat{\Psi}$.

The matrix of uncompensated demand elasticities can be estimated with

$$
\widehat{\mathbf{E}}=D(\mathbf{s})^{-1} \widehat{\boldsymbol{\Theta}}-\widehat{\mathbf{\Psi}}+b_{a} \mathbf{1}_{G} \otimes \widehat{\lambda}^{\prime}
$$

and the matrix of compensated, Hicksian demand elasticities, with

$$
\widehat{\widetilde{\mathbf{E}}}=\widehat{\mathbf{E}}+D(\zeta) D(\mathbf{s})^{-1} \mathbf{1}_{G} \mathbf{s}^{\prime}+b_{a} D(\zeta) \mathbf{1}_{G} \otimes \widehat{\lambda}^{\prime},
$$

where a typical element of the vector $\zeta$ is $\beta_{0}^{g}+s_{g}\left(1-\beta_{1}^{g}\right)$. 


\section{Empirical Results}

I exemplify the use of the method with an application to household data for rural Mexico. In Mexico, a good source of data is the Household Income and Expenditure National Surveys, ENIGH (Encuesta Nacional de Ingresos y Gastos de los Hogares). In this application, I use data from the 1996, 1998, and 2000 rounds. The surveys are representative of the population at the National level, and cover rural and urban areas. Since I am focusing on the impacts of price reforms on wage agricultural income, I use the rural modules only. Table 1 reports some summary statistics.

I begin with sample sizes and number of clusters $c$. The ENIGH is carried out at different weeks in different regions. To make the assumption of common prices in a given cluster $c$ reasonable and at the same time to accommodate credible regional differences in agricultural wages, I define clusters as province-week pairs. There are between 3306 and 4684 rural households in the samples. There are 720 clusters in the pooled sample, approximately 275 in each ENIGH round. The number of households interviewed in each "cluster" is typically larger than in other surveys, with at least 20 households in each of them.

On the consumption side, expenditure data include food and non-food items. Since quantities are only reported for foodstuff, and since I am interested in agricultural reforms, I estimate the model for the following six goods: corn, wheat, dairy, oils \& fats, meat, and fruits \& vegetables. These goods are aggregates of differentiated goods within each category. For instance, corn includes own-consumption, corn grain, and finely grinded corn; meat includes different types of beef, poultry and pork. These varieties are considered homogeneous goods. In rural areas, food consumption includes market purchases and own-consumption. Following Deaton and Grimard (1992), for instance, we compute unit values using market purchases only, but budget shares using all expenditure (purchases plus home production).

Fruits \& Vegetables, Corn and Meat are the major categories of food expenses in the sample. Notice that average unit values for all these food products increase in real terms from 1996 to $2000 .{ }^{11}$ As a result, budget shares decline with time. Notice that the number

\footnotetext{
${ }^{11}$ All data on expenditures and wages are expressed in 2002 constant prices using regional price deflators constructed by the Mexican statistical office. In Table 1, the definition of corn excludes "tortillas".
} 
of households that report quantities (and, thus, unit values) is lower than the number of households in the sample. This is not surprising.

On the income side, information includes agricultural production, wage earnings, capital income, and other sources of income. In the estimation that follows, $a_{h}$ is defined as wage income in agricultural activities (farm employment) and self employment income earned in agriculture. This includes, first, total income from the sale of agricultural production of corn, wheat, and other crops. (Unfortunately, the data do not identify the value of sales of different crops, but just the total income from all agricultural activities). Second, the definition of $a_{h}$ includes wages related to agricultural activities, like off-farm employment and rural labor in the field. We do not know, however, whether these wages are earned in corn, wheat, or dairy production. Overall, agricultural wages as defined above account for around 60 percent of the total income of rural families. Notice that real wages did not change much from 1996 to $2000 .{ }^{12}$

Household characteristics include the size of the family, the demographic composition, and age, gender, marital status, and educational level. These are the controls that I include in the estimation of the first stage. The educational variables (primary school, secondary school, and college dummies), are assumed to affect the wage income (i.e., they belong to the vector $\mathbf{m}_{h c}$ ) but not the consumption decisions (i.e., they do not belong to the demographic vector $\mathbf{z}_{h c}$. This assumption allows me to use these educational variables as instruments in the demand equations. While there might be reasons to include the educational dummies in the demand model, I argue that it is worth allowing for these exclusion restrictions so as to explore the estimation of the model with instrumental variables. In the first stage, I include year dummies as well. ${ }^{13}$

\footnotetext{
${ }^{12}$ It is possible to work with alternative definitions of the wage agricultural income; see section 4.3 for some examples.

${ }^{13}$ Since I am studying the agricultural sector in Mexico, I need to discuss PROCAMPO, a key agricultural policy in the country. PROCAMPO is a program that provides income support to rural farmers. It was implemented in 1994 to replace the policy of support to producer prices that was being eliminated at that time. For my purposes, there are two features of PROCAMPO that I want to highlight. First, the elimination of pan-seasonal and pan-territorial prices in agricultural commodities implies a movement towards market prices. This means that the variation in purged unit values that I use to identify the model truly originates in price differences across clusters. Second, PROCAMPO subsidies are decoupled and thus are not set on the basis on current household behavior or outcomes (like production levels). In other words, lump-sum subsidies are unlikely to affect household behavior. Further, provided PROCAMPO money is spent in the
} 


\subsection{Household Wage Income}

In this section, I discuss the main results concerning the wage price elasticities. I begin with a comparison of the naive model that uses cluster unit values as regressors and the full model proposed here. Given the complexity of the full model, I introduce several simplifications to it and I discuss different settings where these simplifications can be useful.

\subsubsection{Main Results}

Results are shown in Table 2. In column [1], I report the estimates of $\lambda_{g}$ from a naive model that uses average cluster unit values as regressors. I find that $a_{h c}$ is positively and significantly associated with corn prices, with an elasticity of 0.58 and a $t$-statistic of 5.65. Standard errors are corrected for cluster effects. Apart from the price of meat, which appears to affect wage agricultural income positively too, all the four other prices are statistically insignificant.

The remaining columns of Table 2 report results from the full model and its simplifications. Following Deaton (1997), the standard errors are estimated with bootstrap methods by resampling the second stage (clusters) and keeping constant the parameters of the first stage. Column [2] shows estimates from the full model with instrumental variables. The prices of corn and fruits \& vegetables are positively and significantly associated with household agricultural wage income. The elasticity of corn is 0.40 , and that of fruits \& vegetables, 1.29. In contrast, the price dairy is negatively associated with agricultural income, with an elasticity of -1.10 . There is no statistically significant effect of the prices of wheat, oils \& fats, and meat.

The theoretical model of section 2 provides an intuitive interpretation of these results. Corn and Fruits \& Vegetables are arguably agricultural activities of type 1, which employ a

same way as other sources on income, the role of these subsidies in demand will be correctly controlled for by including total household expenditure as a regressor (Case and Deaton, 1998). There are thus good grounds to believe that the presence of PROCAMPO will not affect the estimates and the procedure developed in this paper. Notice, however, that there are instances in which PROCAMPO could affect my results. If, for instance, receiving subsidies encourages some individuals not to participate in labor markets, there might be an unmeasured effect on wages. Since I am not modeling labor supply in this paper, such effects are left for future research. 
large fraction $\mu^{1}$ of the workforce. When the prices of these goods increase, the demand for mobile labor and specific labor of type 1 increase. This leads to increases in the wages of mobile labor and on the return to specific agrarian labor. When the price of dairy increases, instead, there is also an increase in the demand for mobile labor. However, this increase in $w^{m}$ causes a decline in the surplus accruing to specific labor of type 1. If agrarian activities $a g_{j}^{1}$ are important enough, average agricultural income may decline in the end (see Figure 2).

These estimates suggest that the use of average unit values as regressors in the naive model may be incorrect. First, dairy and fruits \& vegetables have statistically significant impacts on household wage agricultural income in the Full Model, but not in the naive model. The price of meat, which is positively related with $a_{h}$ in the naive model, is no longer significant in the Full model. Only in one case, namely corn, do the models deliver comparable elasticities. In the end, the corrections of the Full Model seem important.

Notice that the model recovers the wage price elasticities by comparing regional disparities in prices of agricultural goods and in wages (conditional on other variables). In theory, if labor reallocation is costless, worker would migrate to higher wage localities, thus equalizing wages. In such a setting, national wages would not be affected by regional differences in prices. How can this theory be reconciled with the empirical strategy?

The fact that the Full model estimates wage elasticities that are significantly different from zero suggests that there is some degree of labor immobility and that the model is successful in exploiting this feature of the data. But this success of the model is in fact a consequence of the definition of "cluster" adopted in the paper. In Deaton's work, a cluster is usually a small village. Here, instead, a cluster is defined as a pair (locality-week), where a locality is a "entidad federativa," or province. This has two implications regarding labor mobility and wage disparities. First, since the regional dimension of a cluster is a province, the model only requires certain degree of labor immobility at the province level but not necessarily at the village level. This is indeed a much softer assumption and, in fact, regional disparities in wages in Mexico at the province level have been extensively documented (Hanson, 1997; Roberton, 2000). Second, with the added temporal dimension 
in the definition of a cluster, part of the identification comes from the time series so that the assumption of regional labor immobility becomes less relevant. ${ }^{14}$

\subsubsection{Simplifications and Extensions to the Full Model}

The formulas for the joint estimator proposed in this paper are quite complex. Specifically, the full model requires the estimation of a complete system of demand and agricultural wage income, which implies a lot of work to prepare and compute the matrices of section 3 . If the estimator is going to be used in the evaluation of policies, it seems important to inquire if modified versions of the model can help simplify the formulas. In addition, since the model can only estimate linear regression functions for household outcomes, it may not be used in cases where the outcome involves discrete choices (such as labor supply decisions). Finally, since the model estimates a large number of parameters, there might be efficiency concerns.

In terms of the efficiency and precision of the estimates, an interesting alternative is to assume that unit values are only affected by own prices, so that the cross-price effects in equation (15) are zero. This is not, in fact, such a strong assumption, since the model delivers estimates of the off-diagonal elements of $\boldsymbol{\Psi}$ that are very close to zero. ${ }^{15}$ The diagonal elements of $\Psi$ are instead estimated. Estimation can be carried out as in section 3, but replacing $\widehat{\boldsymbol{\Psi}}$ with $\widetilde{\boldsymbol{\Psi}}$, a diagonal matrix with the elements $\widehat{\psi}_{g g}$ in the diagonal, and zero off-diagonal elements. Results for this model, labeled Alternative 1, are in columns [3] of Table 2. As expected, this version of the model improves the OLS estimation of the naive model and delivers estimates that are close to those in the Full model. Notice, however, that the standard errors are pretty close to those of the full model so that, in the end, efficiency is not really improved in this application (though it might be in others).

Even though Alternative 1 will work well in practice, it is still computationally complex. A more promising simplification is to impose restrictions on the covariance of the error term

\footnotetext{
${ }^{14}$ Unfortunately, there are only 9 "weeks" where data were collected in Mexico and this is not enough to identify such a complex model as the full model only from the time series component of the data. Data permitting, however, this could work as a potential test of the model.

${ }^{15}$ This is true in my case (although I do not report these estimates to save some space) and all other applications of Deaton's model. See Deaton (1988), Deaton (1997), Deaton and Grimard (1992), and Deaton, Parikh, and Subramanian (1994).
} 
in the wage equation. In many instances, it will be possible to rule out the correlation between the error in the wage equation and the errors in both the unit value and the budget share equations. In these settings, the full model can be estimated by OLS (instead of IV) with two main advantages: improvements in precision (perhaps even more than Alternative 1) and softer requirements in terms of exclusion restrictions.

In columns [4] and [5] of Table 2, I report estimates from the Full model and Alternative 1 using OLS in the first stage estimation of the share and unit value equations. In both cases, it is found that higher corn prices are associated with higher agricultural wage income, whereas higher prices of dairy products negatively affect agricultural income. No statistically significant effect is found in the rest of the cases, including fruits \& vegetables (which is significant in the Full model).

A further simplification can be achieved by exploring a model in which the averages of the first stage residuals are in fact zero. This will happen if the number of households in a given cluster is sufficiently large. In those cases where this assumption is valid (and there may be few realistic such cases), the model simplifies significantly. In fact, the variance-covariance corrections of the formulas disappear and the model can be solved much easily. In column [6] of Table 2, I report the results from such a model. Notice how the estimates start to drift apart from those of the full model with IV. Only the elasticities of corn prices remain comparable. Dairy still appear negative and significant but the elasticities $(-0.30$ and -1.10$)$ are quite different.

To end, I believe a naive model that uses average unit values as measures of prices does not perform well - there are too many econometric problems to trust these estimates. Thus, a sensible strategy requires a more thorough model with the added complications in estimation. Efficiency gains can be achieved by assuming a diagonal matrix of price elasticities of qualities with almost no loss in consistency but with little gain in computation. Computational gains and flexibility are bound to occur by imposing more structure on the covariances of the model. Unfortunately, no general guidelines can be given, since the validity of these restrictions will depend on the number of clusters and on the number of households in each cluster. Also, in many instances, economic models can provide hints as to what is reasonable. While the 
assumptions of the models should be carefully checked on a case by case basis, imposing restrictions of the covariances appears as a promising and feasible alternative when a quick policy evaluation is needed.

\subsection{Own- and Cross-price Elasticities}

There are two reasons why the elasticities estimated from the full model can differ from the elasticities in Deaton (1990) model. One issue is that the estimated expenditure elasticities and quality elasticities may be inconsistent if a fraction of household expenditure (the fraction that depends on agricultural wage income) depends on agricultural prices. The second issue is the presence of the "profit effect," the additional income effect generated by the endogenous response of household income. In this section, I assess empirically how important these problems are by comparing the results obtained from the full model with those obtained from Deaton's model.

In Table 3, I report estimates of the expenditure elasticity (or income elasticity) of demand. I begin by discussing the estimates of $\beta_{0}^{g}$ in columns [1] and [2]. Results are mixed: for corn, wheat, and dairy, the estimates from the Full and Deaton models are not too different. These differences are larger in the remaining three goods, oils \& fats, meat, and fruits \& vegetables. In the case of the quality elasticity of expenditure (columns [3] and [4]), the elasticities are not too different. The estimated expenditure elasticities of demand, $\epsilon_{x}^{g}=\left(\beta_{0}^{g} / s_{g}\right)-\beta_{1}^{g}+1$, are displayed in columns [5] and [6]. The differences in these estimates, especially for wheat, dairy, oils \& fats, and fruits \& vegetables, suggest that the correction for endogeneity may be important in practice.

Table 4 shows estimates of the uncompensated (Marshallian) and compensated (Hicksian) own-price elasticities for four models. These are Deaton's original model, the Full Model with instrumental variables, and Alternative 1 (with $\mathbf{\Psi}=\widetilde{\boldsymbol{\Psi}}$ ) and IV, and the covariance-restricted model, Alternative 2. All the own-price elasticities, compensated and uncompensated, are negative and statistically significant. Comparing Deaton's model with the Full Model, I find significant differences in the own-price elasticities for the cases of corn, dairy, and fruits $\&$ vegetables. For wheat, oils \& fats, and meat, the corrections suggested here are less 
important. Alternative 1, which only estimates the own-price responses of unit values, produces results that are close to those of the Full Model. In contrast, Alternative 2, which assumes no cross-equation correlation in the errors and average cluster errors equal to zero, produced results that are closer to those in Deaton model. Notice, however, that standard errors are much smaller in Alternative 2. Similar conclusions emerge from the study of the compensated own-price elasticities.

To explore the role of the endogeneity of expenditure and of the "profit effect" in explaining the differences in the own-price elasticities, it is instructive to decompose these differences between the different models. I do this in Table 5 for the case of the uncompensated elasticities. Column [1] reproduces the own-price elasticities from Deaton's model with exogenous expenditure. In column [2], I isolate the effects of the potential inconsistencies in the estimation of $\beta_{0}^{g}$ and $\beta_{1}^{g}$ that would arise if household income were endogenous. To do this, I reestimate Deaton's model (without the wage equation) using instrumental variables for household expenditure. The role of the "profit effect" can be illustrated by comparing columns [2] with the Full model, column [3]. In the case of corn, the two corrections of this paper decrease the estimated elasticity. The correction for the endogeneity of $x_{h}$ is less important than the "profit effect." In the case of dairy, the corrections of the paper drive the elasticity up, from -1.28 to -1.39 , due to endogeneity, and further up to -2.29 , due to the profit effect. It follows that most of the differences in the estimated elasticities is explained by this last effect - intuitively, an increase in the price of dairy (which reduces consumption) reduces agricultural wage income (with an elasticity of -1.1 in Table 2) and causes a negative income effect that pulls consumption of dairy further down. An interesting case is fruits \& vegetables, where the correction for endogeneity is not really important but the addition of the profit effect renders the demand elasticity statistically insignificant. This is because the increase in the price of fruits \& vegetables has a strong wage effect, and thus a strong positive income effect.

To better understand the role played by the "profit effect," notice that the additional income effects caused by the response of household income to prices have two effects on consumer choices. First, by facing changed incomes, households modify consumption choices 
according to the expenditure elasticity. Second, consumers modify their quality choices according to the quality elasticity of expenditure. This means, first, that there is an additional term in the income effects in demand, and, second, that there is an income effect on quality choices (the third term on the right hand side of (26)).

I separate these two effects in the last two columns of Table 5. In column [4], I correct the matrix $\boldsymbol{\Psi}$ in (26) by including the term $b_{a} D(\xi) D(\mathbf{s}) \mathbf{1}_{G} \otimes \lambda^{\prime}$, but I exclude the term $b_{a} \mathbf{1}_{G} \otimes \lambda$ in equation (27). This term is computed in column [5]. It is observed that the additional income effect in consumption generated by the profit effect is much more important than the quality shading effect of the additional income. Indeed, in column [4], all the effects are small.

For completeness, I report the full set of own- and cross-price compensated and uncompensated demand elasticities for the full model in Table 6. The cross-price elasticities are generally small, and not always statistically significant. This result is in line with those reported in many previous studies and summarized in Deaton (1997).

\subsection{Variants of the "Profit Effect"}

In the standard definition of the development literature, the "profit effect" of a price change is given by the change in income from agricultural production. In the results reported in Tables 2 to 6 , I instead have worked with a broader definition of the profit effect that encompasses both income from agricultural production and earned wages in agriculture. Arguably, the implications of the "profit effect" can be different for households engaged in production vis-à-vis households earning wages. In principle, the model can be used to inspect different versions of the "profit effect." The following results exemplify how to adapt the model to explore these different features of rural economies in developing countries.

In Table 7, I report the wage price elasticities, together with the uncompensated and compensated own-price elasticities from two alternative definitions of the "profit effect." In columns (1)-(3), I only allow income from agricultural production (and not wages) to respond to the price changes; I call this the Agricultural Production Model. In column (4)-(6), instead, I only allow wages in agriculture to respond to the price changes (this is 
thus the Wage Income Model). These models work exactly as the more general one in section 3 , but with these alternative definitions of $a_{h c}$ in equation (6).

The Agricultural Production Model behaves quite like the general model: the prices of corn and of fruits \& vegetables affect income positively and significant; the price of dairy, negatively. The magnitudes of the wage elasticities are similar, too. The Wage Income Model behaves a little bit differently: the elasticity of corn is the same as in previous models; the elasticity of dairy is still negative and significant, but smaller in absolute value $(-0.58$ versus -1.41 and -1.10 ); and the the elasticity of fruits \& vegetables is no longer statistically significant. There are minor differences in the estimates of the demand elasticities across models.

\section{The Method at Work: an Assessment}

In this section, I use the estimated elasticities to assess the role of consumption and income responses in the evaluation of the welfare effects of trade-induced price changes. I perform two different exercises. The first exercise inspects the net consumer-net producer hypothesis. The second exercise evaluates three related trade reforms using my method and competing alternative methods and compares results.

\subsection{Net Consumers and Net Producers}

Since the pioneering work of Deaton (1989) in Thailand, it is customary to state that, after a price increase, net consumers will be hurt while net producers will be benefited. The opposite happens after a drop in prices. I argue here that, while this prediction is true in a static scenario, it may be misleading in a more dynamic setting where households can adjust consumption and income. In this case, the net position of the household is endogenously determined and if household responses are large enough, it is possible for some net consumers to become net producers and be actually benefited by the price increase.

I illustrate this idea by exploring the corn sector, a key commodity produced in rural Mexico. For the sake of exposition only, I work with an exogenous increase in the price 
Figure 3

Net Consumers and Net Producers

Corn in Rural Mexico

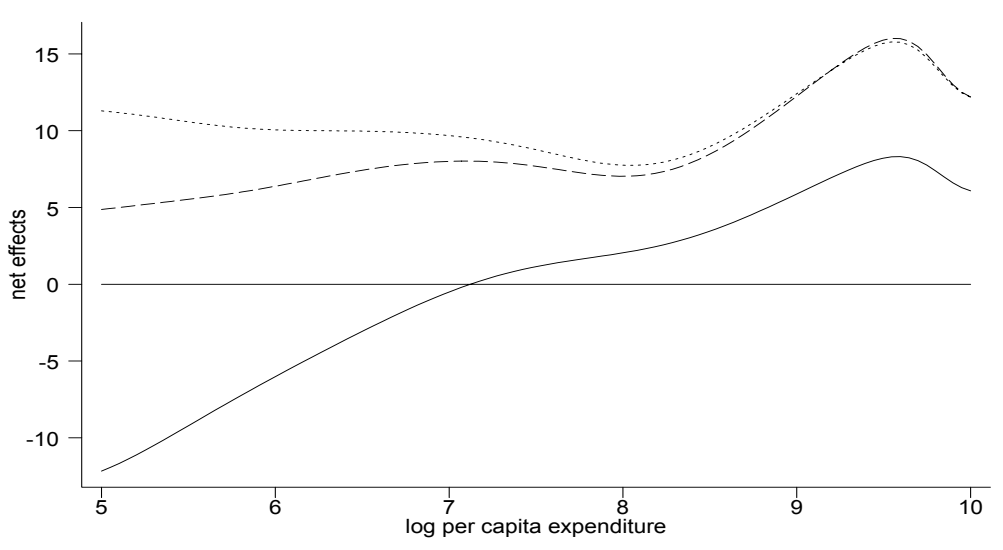

Note: The lines represent the average welfare effects (compensating variations) as a share of household expenditure. The averages are estimated with non-parametric locally weighted regression using a Gaussian kernel and a bandwidth equal to 0.5 . The solid line displays the first order effects given by the difference between corn budget shares and corn income shares. The broken lines allows for income responses and the dotted line, for income and consumption responses.

of corn (say, due to the elimination of domestic support to corn in the U.S.). Following the usual practice in this literature (Deaton, 1989; 1997), I define the welfare effects of the price change as the compensating variation expressed as a share of total household expenditure. In a static scenario, this means that the impacts of the price increase are given by the difference between the share of income from corn production and the share of corn expenditure in total consumption (multiplied by the price change). It is also standard to assess distributional impacts by estimating the average welfare effects across the entire income distribution. These averages are estimated non-parametrically with locally (kernel) weighted regressions. In Figure 3, I plot the static impacts of an increase in the price of corn with a solid line. As expected, households at the bottom of the income distribution are net consumers and households at the top are net producers of corn. In consequence, a price increase hurts the poor but benefits the rich. ${ }^{16}$

\footnotetext{
${ }^{16}$ Notice that the ENIGH does not include information on corn income shares, but rather agricultural income. The corn income shares in Figure 3 are computed using data from the agricultural module of the Encuesta Nacional de Empleo, ENE (National Employment Survey).
} 
I turn now to income responses and I plot the corresponding average welfare effects with a broken line. Here, while income responses are allowed to take place, consumption choices are kept constant. In my model, this means that the agricultural wage income of the household, including corn production and wages from local agricultural markets, reacts to the increase in the price of corn. This response is characterized by the income shares of agricultural wages $a_{h}$ and the wage-price elasticity with respect to corn prices estimated at 0.4 in Table 2. Since quantities consumed are kept constant, consumption impacts are still measured with budget shares. Figure 3 reveals that, in this scenario, an increase in corn prices would benefit households across the entire income distribution. This is because all agricultural income and agricultural wages are responding to the price increase. Naturally, the gains will be smaller (and may become even losses for some households) when alternative definitions of wage agricultural income are used (as in the Agricultural Production or Wage Income Models of section 4.3.

To account for consumption responses, I estimate first and second order impacts using the corn budget share and the own-price elasticity. ${ }^{17}$ In Figure 3, I graph these welfare effects with a dotted line. It is clear that allowing for consumption responses makes the gains even higher. When corn prices increase, consumers reduce quantities so that the initial consumption losses are in the end ameliorated. Notice also that the adjustment of consumption generates larger gains at the bottom of the income distribution. This is because corn is one of the major staples of the poor and thus the adjustment of quantities makes a larger difference for them.

\subsection{Evaluation of Three Trade Reforms}

In the current international forum, developed and developing countries have engaged in negotiations over a Doha Development Round. The negotiations have not been fully successful, but efforts continue and the discussions involve three main policy scenarios. There

\footnotetext{
${ }^{17}$ Let the household expenditure function be given by $e(\mathbf{p}, u)$, for prices $\mathbf{p}$ and required utility $u$. If only the price of good $1, p_{1}$, is allowed to change, a second order Taylor expansion of $e$ (expressed as a share of initial expenditure) gives a compensating variation $c v=s_{1} d \ln p_{1}+(1 / 2) \epsilon_{11} s_{1}\left(d \ln p_{1}\right)^{2}$, where $s_{1}$ is the budget shares and $\epsilon_{11}$ is the own-price elasticity. For simplicity, cross price effects are not computed (although it would be easy to do this given the cross-price elasticities estimated above.
} 
is a Doha Development Agenda (DDA) that most likely will include some elimination of export subsidies and some improvement in market access granted by developed countries, as well as some liberalization of own trade barriers by developing countries. An alternative policy scenario is one of full trade liberalization: all countries commit to eliminate all interventions to international trade. Finally, there is the possibility of own reforms, whereby a given country always has the choice of pursuing unilateral trade liberalization.

In this section, I evaluate these three policy scenarios using my method and some of the competing available methods discussed before (that is, Deaton models of demand elasticities, and the Naive model of agricultural wage income responses). To simplify the analysis, I will focus on the welfare of a representative agent characterized by the average household in rural Mexico (naturally, other criteria can be easily followed). The policy assessment is thus based on a comparison, or ranking, of these average welfare effects.

To begin this assessment, I need a set of price changes caused by the three trade policy scenarios that I can feed into the different evaluation methodologies. I borrow these price changes from a recent comprehensive project by the World Bank which has produced estimates of these different trade reforms using Computable General Equilibrium Models (Hertel and Winters, 2006). While there are deficiencies inherent to CGE modeling, these price changes are good enough to exemplify how the different techniques work. In short, Hertel and Winters model simulate that the Doha Development Agenda would cause prices to increase only slightly. Instead, full multilateral liberalization would cause large increases in the prices of corn and wheat (14 percent) and oils \& fats (15 percent) and slight declines in the prices of dairy and fruits \& vegetables. Own liberalization, lastly, would cause price decline in all goods, especially in dairy and meat. ${ }^{18}$

In the first row of Table 8, I study the consumption effects. I use the compensated demand elasticities from Deaton model without corrections (column [5] of Table 4) and from the Full Model (column [6] of Table 4). There are minor differences in the average welfare effects: both methods suggest losses from the DDA and the full liberalization scenarios (since most prices are going up) and gains from own reforms (since tariff cuts lead to lower prices).

\footnotetext{
${ }^{18}$ See references in Table 8 for details.
} 
There are no reversals in policy rankings (as expected, since consumers are homogeneous in the direction of the welfare effects of price changes - but not in the magnitudes).

To compare income effects (second row of Table 8), I use the wage price elasticities of the full model and of the naive model (columns [2] and [1] of Table 2, respectively). The differences in the welfare effects become much more significant and, in fact, there are reversals in the ranking of different policy option. While the Full Model would find losses from Own Reforms and gains from the DDA and full liberalization, the naive model would instead find losses from the DDA and the full multilateral liberalization and gains from own reforms. These reversals are caused mainly by the differences in the wage price elasticities of Fruits \& Vegetables and Dairy (which are irrelevant in the naive model) and Meat (which is irrelevant in the Full Model).

Finally, the last row of Table 8 reports the overall impacts, the sum of the consumption and income effects. Since the income effects dominate the consumption effects (a recurrent finding in the literature - see Porto, 2006), the conclusions and policy reversals remain unaltered: the Full model would choose Full Trade Liberalization to produce welfare gains and the alternative would choose Own Reforms.

The aim of this paper is not to rank different trade policies and thus I have done this only crudely in this analysis. Notice, for example, that the standard errors attached to the estimates of the welfare effects are quite large, particularly for the income effects. This is because I am exploring global trade reforms that involve six price changes and some of the corresponding wage-price elasticities have large standard errors. Yet the point that I want to emphasize in this section is that the extensions suggested by my method can easily produce reversals in policy rankings when applied to concrete applications. Furthermore, these exercises show that the critical correction is the inclusion of the income effect and the unbiased estimation of the wage-price elasticities, rather than the correction of the demand elasticities. 


\section{Conclusions}

This paper has introduced an empirical model designed to be used in the evaluation of price reforms. These reforms affect households both as consumers and as producers or income earners. The estimation of these impacts if often hard due to lack of price variability at the household level. The simple idea of using unit values as a proxy for prices, which would deliver enough price variation, is problematic because of endogeneity of unit values, biases due to proxy variables, and measurement error. In this paper, I have extended Deaton's work (Deaton, 1987, 1988, 1990) and I have proposed a method that uses unit values as measures of prices, is free from these problems, and accommodates income and consumption responses to price shocks.

The method combines Deaton model of demand with an equation that describes the agricultural wage income of the household. By estimating the demand model together with the quality shading model, I was able to extract the right price signal from unit value data. These data can then be plugged in the wage equation to identify the relevant elasticities. Further, when a fraction of household income is allowed to be endogenous, there are additional effects to consider in the estimation of the demand parameters. First, there

is the "profit effect" whereby a change in an agricultural price causes a change in household income and additional income effects in consumption. Second, the change in household income brings about further quality shading responses that affect the elasticities of demand. In this paper, I have derived formulas to correct for these factors.

The method was applied to the estimation of consumption and agricultural wage income responses to agricultural prices in rural Mexico. It was found that the corrections suggested in this paper can make a difference and should be preferred to a simpler model that uses average cluster unit values as regressors. Failing to control for endogeneity, biases, and measurement errors may lead to inconsistent estimates of the price elasticities and to an incorrect or misleading evaluation of policy changes.

I have assessed the methodology by exploring the workings of competing models after a price change. One exercise was tailored to reveal the role of the joint analysis of consumption and income responses in the evaluation of trade reforms. I have shown that the proposition 
that net consumers will be hurt by price increases whereas net producers will be benefited is only true in a static scenario. When consumers adjust quantities, farmers adjust production, and local labor markets react to the changed prices, net consumers can become net producers, thus benefiting from price increases. Data from rural Mexico support these findings. By investigation three related WTO global trade reforms under different Doha scenarios, another exercise revealed that the use of the proposed method can lead to more accurate rankings of the welfare effects of different policy options. In fact, failure to adopt the major corrections of the Full model can easily lead to reversals of policy options.

Finally, the analysis has shown that the major corrections of my method are the inclusion of the income effects of trade (price) policies and the consistent estimation of the wage-price elasticities; the correction of the demand elasticities due to the "profit effect" is less important in Mexico. In addition, several simplifications of the Full Model were explored and useful simplifications will obtain when economic theory or the structure of the data can justify restrictions on the cross-equation covariance structure. Some of these alternatives could also lead to extensions to estimate non-linear models.

\section{Appendix 1: Quality Model}

This Appendix derives the restriction needed to identify the parameters of the empirical model. Most of this discussion follows Deaton (1997). Within aggregates of goods, such as corn, there are different varieties that a consumer can choose. Low quality corn would comprise whole grain maize or badly ground grains. High quality corn may comprise, for example, high-quality, finely-ground maize meal. It follows that unit values are not the same as prices because households choose quantity and quality simultaneously, thus the need for a joint model of quality and quantity. In fact, a key insight of Deaton's demand model is to exploit consumer choices of quantity and quality to extract price information from unit values.

Let $g$ be a group of goods (corn), which comprises different varieties of homogenous products (grain, maize meal). Due to transportation costs, marketing costs, transaction costs, and local regulations, prices are geographically different (in subsection 2.3 below I discuss this in more details). I denote the price vector of good $g$ in locality (cluster) $c$ by $\mathbf{p}_{c g}$. Since each good within group $g$ is homogenous, the elements of $\mathbf{p}_{c g}$ represent true prices, not unit values. For a typical household in cluster $c$, there is a quantity vector $\mathbf{q}_{c g}$, such that total expenditure on corn is $x_{c g}=\mathbf{p}_{c g} \mathbf{q}_{c g}$. Following Deaton, the price vector $\mathbf{p}_{c g}$ is 
decomposed into an aggregate price level of corn, $\pi_{c g}$, and a vector of relative prices $\mathbf{p}_{g}^{0}$

$$
\mathbf{p}_{c g}=\pi_{c g} \mathbf{p}_{g}^{0}
$$

This requires the existence of a linearly homogeneous function $\pi_{c g}\left(\mathbf{p}_{c g}\right)$ such as a standard price index with fixed weights. Notice that aggregate prices are allowed to vary across localities (clusters) $c$ while the relative prices are held constant.

The definition of quality adopted by Deaton is based on a comparison of relative prices: more expensive goods are assumed to be higher quality goods. Let $Q_{c g}$ be the quantity consumed of the aggregate good $g$ (i.e. corn) and assume that $Q_{c g}=\mathbf{k}_{g} \mathbf{q}_{c g}$, where $\mathbf{k}_{g}$ is defined so that it is possible to aggregate the quantities consumed of the homogenous goods in $\mathbf{q}_{c g}$. As an example, let $\mathbf{q}_{c g}$ be measured in kilos, and let $\mathbf{k}_{g}$ be a vector of ones; then, $Q_{c g}$ is just the total kilograms of corn consumed by the household. Quality $\xi_{c g}$ is defined as

$$
\xi_{c g}=\frac{\mathbf{p}_{g}^{0} \mathbf{q}_{c g}}{\mathbf{k}_{g} \mathbf{q}_{c g}}
$$

so that the higher quantity consumed of the more expensive goods is, the higher the quality is. In fact, with this definition, the price per kilo of corn variety $i$ is $p_{g i}^{0} / k_{g i}$, and varieties with higher ratios are higher-quality varieties. In this model, thus, expenditure can be written as the product of quantity $Q_{c g}$, price $\pi_{c g}$, and quality $\xi_{c g}$.

To close the quality model, it is necessary to impose some structure on preferences, which are henceforth assumed to be separable in the different aggregates of goods. The utility function is

$$
U=V\left[v_{1}\left(q_{1}\right), v_{2}\left(q_{2}\right), \ldots, v_{g}\left(q_{g}\right), \ldots, v_{M}\left(q_{M}\right)\right]
$$

With separable preferences, the upper-tier utility function $V$ is maximized when subgroup utilities $v_{g}$ are individually maximized subject to total expenditure in each group. This means that demands within good $g$ are given by

$$
\mathbf{q}_{c g}=f_{g}\left(x_{c g}, \mathbf{p}_{c g}\right)=f_{g}\left(\frac{x_{c g}}{\pi_{c g}}, \mathbf{p}_{g}^{0}\right)
$$

Quality is a function of quantities $\mathbf{q}_{c g}$, reference prices $\mathbf{p}_{g}^{0}$, and the quantity aggregator $\mathbf{k}_{g}$. Since $\mathbf{p}_{g}^{0}$ and $\mathbf{k}_{g}$ are held constant, $\xi_{c g}$ is in fact a function of the quantity vector $\mathbf{q}_{c g}$ and, given separable preference and group demands $(\mathrm{A} 1), \xi_{c g}$ is in the end a function of the ratio $x_{c g} / \pi_{c g}$. That is,

$$
\text { (A2) } \xi_{c g}=\xi_{c g}\left(\frac{x_{c g}}{\pi_{c g}}, \mathbf{p}_{g}^{0}\right) \text {. }
$$

Equations (A1) and (A2) describe the choices of quantity and quality under separability. This restriction on preferences delivers a relationship between the parameters of the empirical 
model that identifies them. For own-price responses, equation (A2) implies that

$$
\frac{\partial \ln \xi_{g}}{\partial \ln \pi_{g}}=\frac{\partial \ln \xi_{g}}{\partial \ln x_{g}}\left(\frac{\partial \ln x_{g}}{\partial \ln \pi_{g}}-1\right)
$$

Differentiating $\ln x_{g}=\ln \pi_{g}+\ln \xi_{g}+\ln Q_{g}$ and using (A3), I get

(A4) $\frac{\partial \ln \xi_{g}}{\partial \ln \pi_{g}}=\frac{\epsilon_{p}^{g g} \frac{\partial \ln \xi_{g}}{\partial \ln x_{g}}}{1-\frac{\partial \ln \xi_{g}}{\partial \ln x_{g}}}$,

where $\epsilon_{p}^{g g}$ is the own-price elasticity of good $g$. By definition, the expenditure elasticity of quality is $\beta_{1}^{g}=\frac{\partial \ln \xi_{g}}{\partial \ln x}=\frac{\partial \ln \xi_{g}}{\partial \ln x_{g}} \frac{\partial \ln x_{g}}{\partial \ln x}$. From the equality $\ln x_{g}=\ln \pi_{g}+\ln \xi_{g}+\ln Q_{g}$, I get $\frac{\partial \ln x_{g}}{\partial \ln x}=\beta_{1}^{g}+\epsilon_{x}^{g}$, where $\epsilon_{x}^{g}$ is the expenditure elasticity of good $g$. Hence,

(A5) $\frac{\partial \ln \xi_{g}}{\partial \ln \pi_{g}}=\beta_{1}^{g} \frac{\epsilon_{p}^{g g}}{\epsilon_{x}^{g}}$.

Unit values are the product of price and quality, $\ln v_{g}=\ln \pi_{g}+\ln \xi_{g}$; differentiating with respect to $\ln \pi_{g}$ and using (A5), it follows that

(A6) $\psi_{g g}=1+\beta_{1}^{g} \frac{\epsilon_{p}^{g g}}{\epsilon_{x}^{g}}$,

To end, we need to write the restriction imposed by the assumption of separable preferences in terms of the parameters of the model. Unit value, the ratio of expenditure and reported quantity, is given by $v_{c g}=x_{c g} / Q_{c g}$. Differentiating with respect to the price of good $g$, I get

(A7) $\psi_{g g}=\frac{\partial \ln x_{g}}{\partial \ln \pi_{g}}-\epsilon_{p}^{g g}$.

Expenditure on good $g$ is equal to the budget share $s_{g}$ times total expenditure $x$, or $\ln x_{g}=$ $\ln s_{g}+\ln x$. This means that $\frac{\partial \ln x_{g}}{\partial \ln \pi_{g}}=\left(\theta_{g g} / s_{g}\right)+b_{a} \lambda_{g}$, where $\theta_{g g}$ is the own-price elasticity of budget shares and $b_{a} \lambda_{g}$ captures the change in total expenditure caused by the factor income effects of higher prices (see text). It follows that

(A8) $\psi_{g g}=\frac{\theta_{g g}}{s_{g}}+b_{a} \lambda_{g}-\epsilon_{p}^{g g}$.

Next, differentiating the unit value with respect to total expenditure, I get

$$
\beta_{1}^{g}=\frac{\beta_{0}^{g}}{s_{g}}+1-\epsilon_{x}^{g}
$$

Equation (13) for the one-good model or (25) for the multi-good model in the text follow from the combination of (A7), (A8), and (A9). A similar analysis can be carried out for 
cross-price effects.

\section{References}

Barnum, H. and L. Squire (1979). "A model of an Agricultural Household. Theory and Evidence," World Bank Ocassional Papers No 27.

Case, A. and A. Deaton (1998). "Large Cash Transfers to the Elderly in South Africa," The Economic Journal, vol. 108, pp. 1330-1361.

Crawford, I, F. Laisney, and I. Preston (2003) "Estimation of Household Demand Systems with Theoretically Compatible Engel Curves and Unit Value Specifications," Journal of Econometrics, vol. 114, pp. 221-241.

Deaton, A. (1987). "Estimation of Own- and Cross-Price Elasticities From Household Survey Data," Journal of Econometrics, vol. 36, pp. 7-30.

Deaton, A. (1988). "Quality, Quantity, and Spatial Variation of Price," American Economic Review, vol. 78 No 3, pp. 418-430.

Deaton, A. (1989). "Rice Prices and income Distribution in Thailand: A Non-Parametric Analysis," Economic Journal, vol. 99 No 395, pp. 1-37.

Deaton, A. (1990). "Price Elasticities from Survey Data," Journal of Econometrics, vol. 44, pp. 281-309.

Deaton, A. (1997). The Analysis of Household Surveys. A Microeconometric Approach to Development Policy, John Hopkins University Press for the World Bank.

Deaton, A. and J. Muellbauer (1980). "An Almost Ideal Demand System," American Economic Review, vol 70, pp. 312-336.

Deaton, A., and F. Grimard (1992). "Demand Analysis and Tax Reform in Pakistan," Living Standards Measurement Study, Working Paper No 85, The World Bank. 
Deaton, A., K. Parikh, and S. Subramanian (1994). "Food Demand Patterns and Pricing Policiy in Maharashtra: an Analysis Using Household-Level Survey Data," Sarvekshana, 17, pp. $7-19$.

Edmonds, E. and N. Pavcnik (2005). "The Effects of Trade Liberalization on Child Labor," Journal of International Economics, vol. 65, pp. 401-419.

Edmonds, E. and N. Pavcnik (2006). "Trade Liberalization and the Allocation of Labor between Households and Markets in a Poor Country," Journal of International Economics, vol. 69 , pp. 272-295.

Goldberg, P. and M. Knetter (1997). "Goods Prices and Exchange Rates: What Have We Learned?" Journal of Economic Literature, vol. XXXV, pp. 1243-1272.

Hanson, G. (1997). "Increasing Returns, Trade, and the Regional Structure of Wages," The Economic Journal, vol. 107, pp. 113-133.

Hertel, T. and A.L. Winters (Eds.), (2006). Poverty Impacts of the Doha Development Agenda, Palgrave-McMillan for the World Bank, Washington DC.

Nicita, A. (2006). "The Price Effect of Trade Liberalization: Measuring the Impact on Household Welfare," mimeo, The World Bank.

Porto, G. (2006). "Using Survey Data to Assess the The Distributional Effects of Trade Policies," forthcoming Journal of International Economics.

Ravallion, M. (1990). "Rural Welfare Effects of Food Price Changes Under Induced Wage Responses: Theory and Evidence for Bangladesh," Oxford Economic Papers, vol. 42, pp. $574-585$.

Robertson, R. (2000). "Wage Shocks and North American Labor- Market Integration," American Economic Review, vol. 90, pp. 742-764.

Singh, I., L. Squire, and J. Strauss, eds. (1986). Agricultural Household Models: Extensions, Applications and Policy. Baltimore, Johns Hopkins Press for the World Bank. 
Wolak, F. A. (1996). "The Welfare Impacts of Competitive Telecommunications Supply: A Household-Level Analysis," Brookings Papers on Economic Activity Microeconomics, vol. 1996, pp. 269-340. 
Table 1

Summary Statistics

\begin{tabular}{|c|c|c|c|}
\hline & 1996 & 1998 & 2000 \\
\hline \multicolumn{4}{|l|}{ Sample Sizes } \\
\hline households & 4684 & 3925 & 3306 \\
\hline clusters & 269 & 277 & 274 \\
\hline \multicolumn{4}{|l|}{ Corn } \\
\hline avg. budget share & 10.8 & 9.5 & 6.4 \\
\hline avg. log unit value & 0.82 & 1.18 & 1.40 \\
\hline number of obs. in eq (3) & 3127 & 2693 & 2364 \\
\hline \multicolumn{4}{|l|}{ Wheat } \\
\hline avg. budget share & 3.5 & 3.1 & 2.4 \\
\hline avg. log unit value & 2.24 & 2.38 & 2.54 \\
\hline number of obs. in eq (3) & 3415 & 2816 & 2491 \\
\hline \multicolumn{4}{|l|}{ Dairy } \\
\hline avg. budget share & 3.6 & 3.8 & 3.1 \\
\hline avg. log unit value & 2.01 & 2.38 & 2.54 \\
\hline number of obs. in eq (3) & 2254 & 1947 & 1881 \\
\hline \multicolumn{4}{|l|}{ Oils \& Fats } \\
\hline avg. budget share & 2.5 & 2.2 & 1.4 \\
\hline avg. log unit value & 2.23 & 2.30 & 2.31 \\
\hline number of obs. in eq (3) & 2681 & 1911 & 1710 \\
\hline \multicolumn{4}{|l|}{ Meat } \\
\hline avg. budget share & 6.8 & 6.9 & 5.6 \\
\hline avg. log unit value & 2.91 & 3.22 & 3.33 \\
\hline number of obs. in eq (3) & 2905 & 2436 & 2330 \\
\hline \multicolumn{4}{|l|}{ Fruits \& Vegetables } \\
\hline avg. budget share & 12.1 & 13.2 & 9.1 \\
\hline avg. $\log$ unit value & 1.66 & 2.11 & 2.10 \\
\hline number of obs. in eq (3) & 4222 & 3435 & 2950 \\
\hline \multicolumn{4}{|l|}{ Agricultural Wages } \\
\hline avg. $(\log )$ & 6.41 & 6.44 & 6.45 \\
\hline share of total income & 61.1 & 62.3 & 59.2 \\
\hline number of obs. in eq (4) & 2597 & 1937 & 1607 \\
\hline Avg. per capita expend. (log) & 6.21 & 6.14 & 6.54 \\
\hline Household size & 5.2 & 4.7 & 4.6 \\
\hline Males & 50.2 & 50.1 & 50.1 \\
\hline$\leq 16$ yrs & 38.5 & 35.5 & 34.9 \\
\hline$>16 \& \leq 60 \mathrm{yrs}$ & 49.4 & 49.7 & 49.8 \\
\hline$>60$ yrs. & 12.1 & 14.9 & 15.2 \\
\hline Years of education & 3.5 & 3.4 & 3.5 \\
\hline
\end{tabular}

Note: Own calculations based on the Encuesta Nacional de Ingreso y Gasto de los Hogares (ENIGH). 
Table 2

Applying the Methodology: Wage-Price Elasticities

Naive Model, Full Model and Simplifications

\begin{tabular}{lcccccc}
\hline \hline \multirow{2}{*}{ Naive } & \multirow{2}{*}{ Full } & \multicolumn{4}{c}{ Simplifications } \\
\cline { 4 - 7 } & Model & Model & Alt. 1 & Full Model & Alt. 1 & Alt.2 \\
& & IV & IV & OLS & OLS & OLS \\
& $(1)$ & $(2)$ & $(3)$ & $(4)$ & $(5)$ & $(6)$ \\
\hline \multirow{2}{*}{ Corn } & 0.58 & 0.40 & 0.39 & 0.64 & 0.67 & 0.59 \\
Wheat & $(0.10)$ & $(0.19)$ & $(0.19)$ & $(0.20)$ & $(0.21)$ & $(0.12)$ \\
& -0.05 & -0.28 & -0.37 & -0.26 & -0.29 & -0.13 \\
Dairy & $(0.13)$ & $(0.19)$ & $(0.17)$ & $(0.18)$ & $(0.16)$ & $(0.11)$ \\
& -0.07 & -1.10 & -1.08 & -0.59 & -0.59 & -0.30 \\
Oils \& Fats & $(0.06)$ & $(0.18)$ & $(0.19)$ & $(0.15)$ & $(0.14)$ & $(0.06)$ \\
& -0.01 & -0.48 & -0.44 & -0.78 & -0.72 & -0.47 \\
Meat & $(0.30)$ & $(0.65)$ & $(0.63)$ & $(0.53)$ & $(0.51)$ & $(0.24)$ \\
& 0.45 & -0.45 & -0.42 & -0.09 & -0.05 & -0.03 \\
Fruits \& Vegetables & 0.10 & $(0.27)$ & $(0.25)$ & $(0.28)$ & $(0.27)$ & $(0.16)$ \\
& $(0.18)$ & $(0.47)$ & $(0.49)$ & $(0.41)$ & $(0.41)$ & $(0.19)$ \\
\hline \hline
\end{tabular}

(1) Naive model with average cluster unit values (standard errors are cluster corrected)

(2) Full Model using instrumental variables

(3) Alternative 1: $\tilde{\mathbf{\Psi}}=D(\operatorname{vecdiag}(\widehat{\mathbf{\Psi}}))$ with instrumental variables

(4) Full Model using OLS

(5) Alternative 1 with OLS

(6) Alternative 2: assumes average error in cluster $c$ is zero

All models include additional controls, such as demographics, education, age, gender and year dummies.

The standard errors (in parenthesis) for the models in columns (2) to (6) are computed by bootstrapping the second stage. 
Table 3

Applying the Methodology

Expenditure Elasticities of Quantity and Quality

\begin{tabular}{|c|c|c|c|c|c|c|c|}
\hline & \multicolumn{2}{|c|}{$\beta_{0}$} & \multicolumn{2}{|c|}{$\beta_{1}$} & \multicolumn{2}{|c|}{$\epsilon_{x}$} & \multirow{2}{*}{$\begin{array}{c}\text { Average } \\
\text { Budget } \\
\text { Share } \\
(7)\end{array}$} \\
\hline & $\begin{array}{c}\text { Deaton } \\
(1)\end{array}$ & $\begin{array}{c}\text { Full } \\
\text { Model } \\
(2)\end{array}$ & $\begin{array}{c}\text { Deaton } \\
(3)\end{array}$ & $\begin{array}{c}\text { Full } \\
\text { Model } \\
(4)\end{array}$ & $\begin{array}{c}\text { Deaton } \\
(5)\end{array}$ & $\begin{array}{c}\text { Full } \\
\text { Model } \\
(6) \\
\end{array}$ & \\
\hline Corn & $\begin{array}{l}-0.041 \\
(0.001)\end{array}$ & $\begin{array}{l}-0.042 \\
(0.004)\end{array}$ & $\begin{array}{c}0.094 \\
(0.008)\end{array}$ & $\begin{array}{c}0.126 \\
(0.050)\end{array}$ & 0.441 & 0.396 & 0.088 \\
\hline Wheat & $\begin{array}{l}-0.006 \\
(0.001)\end{array}$ & $\begin{array}{l}-0.009 \\
(0.002)\end{array}$ & $\begin{array}{c}0.064 \\
(0.008)\end{array}$ & $\begin{array}{c}0.087 \\
(0.025)\end{array}$ & 0.721 & 0.614 & 0.030 \\
\hline Dairy & $\begin{array}{l}-0.001 \\
(0.001)\end{array}$ & $\begin{array}{c}-0.004 \\
(0.003)\end{array}$ & $\begin{array}{c}0.019 \\
(0.020)\end{array}$ & $\begin{array}{l}-0.018 \\
(0.068)\end{array}$ & 0.964 & 0.903 & 0.035 \\
\hline Oils \& Fats & $\begin{array}{c}-0.007 \\
(0.0002)\end{array}$ & $\begin{array}{l}-0.015 \\
(0.001)\end{array}$ & $\begin{array}{c}0.018 \\
(0.005)\end{array}$ & $\begin{array}{l}-0.006 \\
(0.016)\end{array}$ & 0.632 & 0.290 & 0.020 \\
\hline Meat & $\begin{array}{c}0.011 \\
(0.001)\end{array}$ & $\begin{array}{c}0.001 \\
(0.004)\end{array}$ & $\begin{array}{c}0.075 \\
(0.006)\end{array}$ & $\begin{array}{c}0.113 \\
(0.019)\end{array}$ & 1.089 & 0.906 & 0.064 \\
\hline Fruits \& Vegetables & $\begin{array}{l}-0.045 \\
(0.001)\end{array}$ & $\begin{array}{c}-0.055 \\
(0.004)\end{array}$ & $\begin{array}{c}0.009 \\
(0.006)\end{array}$ & $\begin{array}{c}0.015 \\
(0.040)\end{array}$ & 0.598 & 0.505 & 0.115 \\
\hline
\end{tabular}

(1) and (2) Expenditure elasticity of budget shares $\left(\beta_{0}\right)$ from Deaton and Full models

(3) and (4) Quality Elasticity $\left(\beta_{1}\right)$ from Deaton and Full models

$(5)$ and (6) Expenditure elasticity of demand $\left(\epsilon_{x}\right)$ from Deaton and Full models

(7) Average budget Share in the sample

Standard errors in parenthesis 
Table 4

Compensated and Uncompensated Own-Price Elasticities Deaton Model and Full Model with Instrumental Variables

\begin{tabular}{|c|c|c|c|c|c|c|c|c|}
\hline & \multicolumn{4}{|c|}{ Uncompensated } & \multicolumn{4}{|c|}{ Compensated } \\
\hline & $\begin{array}{c}\text { Deaton } \\
(1)\end{array}$ & $\begin{array}{c}\text { Full } \\
\text { Model } \\
(2)\end{array}$ & $\begin{array}{c}\text { Alt. } 1 \\
(3)\end{array}$ & $\begin{array}{l}\text { Alt. } 2 \\
(4)\end{array}$ & $\begin{array}{c}\text { Deaton } \\
(5)\end{array}$ & $\begin{array}{c}\text { Full } \\
\text { Model } \\
(6)\end{array}$ & $\begin{array}{l}\text { Alt. } 1 \\
(7)\end{array}$ & $\begin{array}{c}\text { Alt. } 2 \\
(8)\end{array}$ \\
\hline Corn & $\begin{array}{l}-0.92 \\
(0.05)\end{array}$ & $\begin{array}{l}-0.65 \\
(0.09)\end{array}$ & $\begin{array}{l}-0.66 \\
(0.09)\end{array}$ & $\begin{array}{l}-1.00 \\
(0.04)\end{array}$ & $\begin{array}{l}-0.88 \\
(0.05)\end{array}$ & $\begin{array}{l}-0.61 \\
(0.09)\end{array}$ & $\begin{array}{l}-0.62 \\
(0.09)\end{array}$ & $\begin{array}{l}-0.96 \\
(0.04)\end{array}$ \\
\hline Wheat & $\begin{array}{l}-1.34 \\
(0.09)\end{array}$ & $\begin{array}{l}-1.44 \\
(0.13)\end{array}$ & $\begin{array}{c}-1.44 \\
(0.11)\end{array}$ & $\begin{array}{l}-1.22 \\
(0.06)\end{array}$ & $\begin{array}{l}-1.32 \\
(0.09)\end{array}$ & $\begin{array}{l}-1.43 \\
(0.13)\end{array}$ & $\begin{array}{l}-1.43 \\
(0.12)\end{array}$ & $\begin{array}{l}-1.17 \\
(0.06)\end{array}$ \\
\hline Dairy & $\begin{array}{l}-1.28 \\
(0.12)\end{array}$ & $\begin{array}{l}-2.29 \\
(0.24)\end{array}$ & $\begin{array}{l}-2.12 \\
(0.23)\end{array}$ & $\begin{array}{l}-1.16 \\
(0.05)\end{array}$ & $\begin{array}{l}-1.24 \\
(0.12)\end{array}$ & $\begin{array}{l}-2.28 \\
(0.24)\end{array}$ & $\begin{array}{l}-2.11 \\
(0.23)\end{array}$ & $\begin{array}{l}-1.12 \\
(0.05)\end{array}$ \\
\hline Oils \& Fats & $\begin{array}{l}-0.77 \\
(0.34)\end{array}$ & $\begin{array}{l}-1.07 \\
(0.63)\end{array}$ & $\begin{array}{l}-1.04 \\
(0.64)\end{array}$ & $\begin{array}{l}-0.73 \\
(0.15)\end{array}$ & $\begin{array}{l}-0.76 \\
(0.34)\end{array}$ & $\begin{array}{l}-1.07 \\
(0.63)\end{array}$ & $\begin{array}{l}-1.03 \\
(0.64)\end{array}$ & $\begin{array}{l}-0.70 \\
(0.15)\end{array}$ \\
\hline Meat & $\begin{array}{l}-1.35 \\
(0.22)\end{array}$ & $\begin{array}{l}-1.46 \\
(0.24)\end{array}$ & $\begin{array}{l}-1.46 \\
(0.23)\end{array}$ & $\begin{array}{l}-1.09 \\
(0.11)\end{array}$ & $\begin{array}{l}-1.28 \\
(0.22)\end{array}$ & $\begin{array}{l}-1.42 \\
(0.25)\end{array}$ & $\begin{array}{l}-1.42 \\
(0.24)\end{array}$ & $\begin{array}{l}-1.04 \\
(0.11)\end{array}$ \\
\hline Fruits \& Vegetables & $\begin{array}{l}-0.90 \\
(0.13)\end{array}$ & $\begin{array}{l}-0.12 \\
(0.30)\end{array}$ & $\begin{array}{l}-0.10 \\
(0.32)\end{array}$ & $\begin{array}{l}-0.93 \\
(0.06)\end{array}$ & $\begin{array}{l}-0.83 \\
(0.13)\end{array}$ & $\begin{array}{l}-0.01 \\
(0.31)\end{array}$ & $\begin{array}{l}0.001 \\
(0.33)\end{array}$ & $\begin{array}{c}-0.89 \\
(0.06)\end{array}$ \\
\hline
\end{tabular}

Note: Deaton Model is based on Deaton (1990). The Full Model is estimated with instrumental variables. Alternative 1 uses $\tilde{\mathbf{\Psi}}=D(\operatorname{vecdiag}(\widehat{\boldsymbol{\Psi}}))$. Standard errors in parenthesis. 
Table 5

Decomposition of Uncompensated Own-Price Elasticities Deaton Model and Full Model with Instrumental Variables

\begin{tabular}{|c|c|c|c|c|c|}
\hline & \multirow[b]{2}{*}{$\begin{array}{l}\text { Deaton } \\
\text { (1) }\end{array}$} & \multirow[b]{2}{*}{$\begin{array}{c}\text { Endogeneity } \\
\text { of hh income } \\
(2)\end{array}$} & \multirow[b]{2}{*}{$\begin{array}{l}\text { Full } \\
\text { Model } \\
(3)\end{array}$} & \multicolumn{2}{|c|}{ Profit Effect } \\
\hline & & & & $\begin{array}{c}\text { Quality } \\
\text { Effect } \\
(4)\end{array}$ & $\begin{array}{c}\text { Income } \\
\text { Effect } \\
(5) \\
\end{array}$ \\
\hline Corn & $\begin{array}{l}-0.92 \\
(0.05)\end{array}$ & $\begin{array}{l}-0.83 \\
(0.04)\end{array}$ & $\begin{array}{l}-0.65 \\
(0.09)\end{array}$ & $\begin{array}{l}-0.06 \\
(0.03)\end{array}$ & $\begin{array}{c}0.24 \\
(0.12)\end{array}$ \\
\hline Wheat & $\begin{array}{l}-1.34 \\
(0.09)\end{array}$ & $\begin{array}{l}-1.24 \\
(0.08)\end{array}$ & $\begin{array}{c}-1.44 \\
(0.13)\end{array}$ & $\begin{array}{c}0.03 \\
(0.02)\end{array}$ & $\begin{array}{c}-0.23 \\
(0.12)\end{array}$ \\
\hline Dairy & $\begin{array}{l}-1.28 \\
(0.12)\end{array}$ & $\begin{array}{l}-1.39 \\
(0.14)\end{array}$ & $\begin{array}{c}-2.29 \\
(0.24)\end{array}$ & $\begin{array}{c}-0.23 \\
(0.05)\end{array}$ & $\begin{array}{c}-0.67 \\
(0.11)\end{array}$ \\
\hline Oils \& Fats & $\begin{array}{l}-0.77 \\
(0.34)\end{array}$ & $\begin{array}{l}-0.80 \\
(0.38)\end{array}$ & $\begin{array}{l}-1.07 \\
(0.63)\end{array}$ & $\begin{array}{c}0.01 \\
(0.03)\end{array}$ & $\begin{array}{c}-0.29 \\
(0.40)\end{array}$ \\
\hline Meat & $\begin{array}{l}-1.35 \\
(0.22)\end{array}$ & $\begin{array}{l}-1.23 \\
(0.19)\end{array}$ & $\begin{array}{l}-1.46 \\
(0.24)\end{array}$ & $\begin{array}{c}0.05 \\
(0.03)\end{array}$ & $\begin{array}{l}-0.28 \\
(0.17)\end{array}$ \\
\hline Fruits \& Vegetables & $\begin{array}{l}-0.90 \\
(0.13)\end{array}$ & $\begin{array}{l}-0.86 \\
(0.13)\end{array}$ & $\begin{array}{c}-0.12 \\
(0.30)\end{array}$ & $\begin{array}{l}-0.04 \\
(0.02)\end{array}$ & $\begin{array}{c}0.79 \\
(0.29)\end{array}$ \\
\hline
\end{tabular}

Note: Estimates based on the Full model with instrumental variables. 
Table 6

Uncompensated and Compensated Own- and Cross-Price Elasticities Full Model with Instrumental Variables

\begin{tabular}{|c|c|c|c|c|c|c|}
\hline & Corn & Wheat & Dairy & $\begin{array}{c}\text { Oils \& } \\
\text { Fats }\end{array}$ & Meat & $\begin{array}{c}\text { Fruits \& } \\
\text { Vegetables }\end{array}$ \\
\hline \multicolumn{7}{|c|}{ (a) Uncompensated Elasticities } \\
\hline Corn & $\begin{array}{c}-0.65 \\
(0.09)\end{array}$ & $\begin{array}{c}0.33 \\
(0.13)\end{array}$ & $\begin{array}{c}0.95 \\
(0.26)\end{array}$ & $\begin{array}{c}0.24 \\
(0.18)\end{array}$ & $\begin{array}{c}0.04 \\
(0.12)\end{array}$ & $\begin{array}{c}0.13 \\
(0.12)\end{array}$ \\
\hline Wheat & $\begin{array}{c}0.00 \\
(0.11)\end{array}$ & $\begin{array}{l}-1.44 \\
(0.13)\end{array}$ & $\begin{array}{c}-0.05 \\
(0.28)\end{array}$ & $\begin{array}{c}-0.96 \\
(0.17)\end{array}$ & $\begin{array}{c}-0.16 \\
(0.13)\end{array}$ & $\begin{array}{c}-0.30 \\
(0.12)\end{array}$ \\
\hline Dairy & $\begin{array}{c}-0.34 \\
(0.09)\end{array}$ & $\begin{array}{l}-0.55 \\
(0.11)\end{array}$ & $\begin{array}{l}-2.29 \\
(0.24)\end{array}$ & $\begin{array}{l}-0.87 \\
(0.16)\end{array}$ & $\begin{array}{c}-0.63 \\
(0.13)\end{array}$ & $\begin{array}{c}-0.76 \\
(0.12)\end{array}$ \\
\hline Oils \& Fats & $\begin{array}{l}-0.37 \\
(0.32)\end{array}$ & $\begin{array}{l}-0.00 \\
(0.41)\end{array}$ & $\begin{array}{l}-0.38 \\
(0.85)\end{array}$ & $\begin{array}{l}-1.07 \\
(0.63)\end{array}$ & $\begin{array}{l}-0.39 \\
(0.50)\end{array}$ & $\begin{array}{l}-0.00 \\
(0.45)\end{array}$ \\
\hline Meat & $\begin{array}{l}-0.30 \\
(0.15)\end{array}$ & $\begin{array}{l}-0.21 \\
(0.18)\end{array}$ & $\begin{array}{c}0.31 \\
(0.38)\end{array}$ & $\begin{array}{c}-0.14 \\
(0.27)\end{array}$ & $\begin{array}{l}-1.46 \\
(0.24)\end{array}$ & $\begin{array}{l}-0.09 \\
(0.20)\end{array}$ \\
\hline Fruits \& Vegetables & $\begin{array}{c}0.54 \\
(0.24)\end{array}$ & $\begin{array}{c}0.66 \\
(0.29)\end{array}$ & $\begin{array}{c}0.86 \\
(0.64)\end{array}$ & $\begin{array}{c}1.41 \\
(0.43)\end{array}$ & $\begin{array}{c}1.29 \\
(0.32)\end{array}$ & $\begin{array}{l}-0.12 \\
(0.30)\end{array}$ \\
\hline \multicolumn{7}{|c|}{ (b) Compensated Elasticities } \\
\hline Corn & $\begin{array}{l}-0.61 \\
(0.09)\end{array}$ & $\begin{array}{c}0.38 \\
(0.13)\end{array}$ & $\begin{array}{c}1.03 \\
(0.27)\end{array}$ & $\begin{array}{c}0.27 \\
(0.18)\end{array}$ & $\begin{array}{c}0.13 \\
(0.13)\end{array}$ & $\begin{array}{c}0.19 \\
(0.12)\end{array}$ \\
\hline Wheat & $\begin{array}{c}0.01 \\
(0.11)\end{array}$ & $\begin{array}{l}-1.43 \\
(0.13)\end{array}$ & $\begin{array}{l}-0.04 \\
(0.28)\end{array}$ & $\begin{array}{l}-0.96 \\
(0.17)\end{array}$ & $\begin{array}{l}-0.14 \\
(0.14)\end{array}$ & $\begin{array}{l}-0.30 \\
(0.12)\end{array}$ \\
\hline Dairy & $\begin{array}{l}-0.35 \\
(0.10)\end{array}$ & $\begin{array}{c}-0.54 \\
(0.12)\end{array}$ & $\begin{array}{l}-2.28 \\
(0.24)\end{array}$ & $\begin{array}{c}-0.86 \\
(0.16)\end{array}$ & $\begin{array}{c}-0.64 \\
(0.13)\end{array}$ & $\begin{array}{c}-0.78 \\
(0.12)\end{array}$ \\
\hline Oils \& Fats & $\begin{array}{l}-0.38 \\
(0.33)\end{array}$ & $\begin{array}{c}0.00 \\
(0.42)\end{array}$ & $\begin{array}{l}-0.37 \\
(0.86)\end{array}$ & $\begin{array}{l}-1.07 \\
(0.63)\end{array}$ & $\begin{array}{l}-0.39 \\
(0.51)\end{array}$ & $\begin{array}{l}-0.01 \\
(0.47)\end{array}$ \\
\hline Meat & $\begin{array}{c}-0.29 \\
(0.16)\end{array}$ & $\begin{array}{c}-0.18 \\
(0.18)\end{array}$ & $\begin{array}{c}0.36 \\
(0.39)\end{array}$ & $\begin{array}{l}-0.13 \\
(0.27)\end{array}$ & $\begin{array}{l}-1.42 \\
(0.25)\end{array}$ & $\begin{array}{l}-0.08 \\
(0.20)\end{array}$ \\
\hline Fruits \& Vegetables & $\begin{array}{c}0.61 \\
(0.24)\end{array}$ & $\begin{array}{c}0.74 \\
(0.29)\end{array}$ & $\begin{array}{c}0.98 \\
(0.65)\end{array}$ & $\begin{array}{c}1.44 \\
(0.44)\end{array}$ & $\begin{array}{c}1.44 \\
(0.33)\end{array}$ & $\begin{array}{l}-0.01 \\
(0.31)\end{array}$ \\
\hline
\end{tabular}

Note: Estimates based on the Full model with instrumental variables. Standard errors in parenthesis. 
Table 7

Alternative Definitions of the "Profit Effect"

Wage and Demand Price Elasticities

\begin{tabular}{|c|c|c|c|c|c|c|}
\hline & \multicolumn{3}{|c|}{ Agricultural Production Model } & \multicolumn{3}{|c|}{ Wage Income Model } \\
\hline & $\begin{array}{c}\text { Wage } \\
\lambda \\
(1) \\
\end{array}$ & $\begin{array}{c}\text { Demand } \\
\text { uncompensated } \\
(2) \\
\end{array}$ & $\begin{array}{c}\text { Demand } \\
\text { compensated } \\
(3) \\
\end{array}$ & $\begin{array}{c}\text { Wage } \\
\lambda \\
(4) \\
\end{array}$ & $\begin{array}{c}\text { Demand } \\
\text { uncompensated } \\
(5)\end{array}$ & $\begin{array}{c}\text { Demand } \\
\text { compensated } \\
(6) \\
\end{array}$ \\
\hline Corn & $\begin{array}{c}0.55 \\
(0.23)\end{array}$ & $\begin{array}{l}-0.67 \\
(0.07)\end{array}$ & $\begin{array}{l}-0.63 \\
(0.07)\end{array}$ & $\begin{array}{c}0.41 \\
(0.12)\end{array}$ & $\begin{array}{l}-0.76 \\
(0.05)\end{array}$ & $\begin{array}{c}-0.72 \\
(0.05)\end{array}$ \\
\hline Wheat & $\begin{array}{l}-0.46 \\
(0.29)\end{array}$ & $\begin{array}{l}-1.39 \\
(0.12)\end{array}$ & $\begin{array}{l}-1.38 \\
(0.13)\end{array}$ & $\begin{array}{l}-0.40 \\
(0.14)\end{array}$ & $\begin{array}{l}-1.32 \\
(0.08)\end{array}$ & $\begin{array}{l}-1.30 \\
(0.08)\end{array}$ \\
\hline Dairy & $\begin{array}{l}-1.41 \\
(0.24)\end{array}$ & $\begin{array}{l}-2.12 \\
(0.22)\end{array}$ & $\begin{array}{l}-2.11 \\
(0.22)\end{array}$ & $\begin{array}{l}-0.58 \\
(0.13)\end{array}$ & $\begin{array}{l}-1.58 \\
(0.16)\end{array}$ & $\begin{array}{l}-1.55 \\
(0.16)\end{array}$ \\
\hline Oils \& Fats & $\begin{array}{c}0.49 \\
(0.82)\end{array}$ & $\begin{array}{l}-0.62 \\
(0.56)\end{array}$ & $\begin{array}{l}-0.60 \\
(0.56)\end{array}$ & $\begin{array}{l}-0.96 \\
(0.47)\end{array}$ & $\begin{array}{l}-1.02 \\
(0.43)\end{array}$ & $\begin{array}{l}-1.01 \\
(0.43)\end{array}$ \\
\hline Meat & $\begin{array}{l}-0.73 \\
(0.40)\end{array}$ & $\begin{array}{l}-1.46 \\
(0.23)\end{array}$ & $\begin{array}{l}-1.42 \\
(0.23)\end{array}$ & $\begin{array}{c}0.28 \\
(0.24)\end{array}$ & $\begin{array}{l}-1.18 \\
(0.19)\end{array}$ & $\begin{array}{l}-1.11 \\
(0.19)\end{array}$ \\
\hline Fruits \& Vegetables & $\begin{array}{c}1.32 \\
(0.61)\end{array}$ & $\begin{array}{l}-0.38 \\
(0.25)\end{array}$ & $\begin{array}{l}-0.29 \\
(0.26)\end{array}$ & $\begin{array}{c}0.36 \\
(0.36)\end{array}$ & $\begin{array}{l}-0.78 \\
(0.14)\end{array}$ & $\begin{array}{l}-0.72 \\
(0.15)\end{array}$ \\
\hline
\end{tabular}

Note: Estimates from models with alternative definitions of the profit effect. In the Agricultural Production Model, the wage equation includes only income from agricultural activities; in the Wage Income Model, the wage equation includes only wages earned in agriculture. For each of these models, the wage-price elasticities $(\lambda)$, and the uncompensated and compensated demand elasticities are estimated with the Full Model. Standard errors in parenthesis. 
Table 8

Welfare Rankings of Selected Trade Policies

Doha DDA, Full Liberalization, and Own Reform

\begin{tabular}{|c|c|c|c|c|c|c|}
\hline & \multicolumn{3}{|c|}{ Full Model } & \multicolumn{3}{|c|}{ Alternative Methodologies } \\
\hline & $\begin{array}{c}\text { Doha } \\
\text { DDA } \\
(1) \\
\end{array}$ & $\begin{array}{c}\text { Full } \\
\text { Liberalization } \\
(2)\end{array}$ & $\begin{array}{c}\text { Own } \\
\text { Reform } \\
(3)\end{array}$ & $\begin{array}{l}\text { Doha } \\
\text { DDA } \\
(4) \\
\end{array}$ & $\begin{array}{c}\text { Full } \\
\text { Liberalization } \\
(5)\end{array}$ & $\begin{array}{c}\text { Own } \\
\text { Reform } \\
(6)\end{array}$ \\
\hline Consumption Effects & $\begin{array}{c}-0.148 \\
(0.0004)\end{array}$ & $\begin{array}{l}-1.225 \\
(0.012)\end{array}$ & $\begin{array}{c}1.609 \\
(0.007)\end{array}$ & $\begin{array}{c}-0.148 \\
(0.0002)\end{array}$ & $\begin{array}{l}-1.213 \\
(0.007)\end{array}$ & $\begin{array}{l}1.590 \\
(0.005)\end{array}$ \\
\hline Income Effects & $\begin{array}{c}0.549 \\
(1.169)\end{array}$ & $\begin{array}{c}4.293 \\
(6.313)\end{array}$ & $\begin{array}{l}-7.913 \\
(2.527)\end{array}$ & $\begin{array}{c}-0.188 \\
(0.538)\end{array}$ & $\begin{array}{l}-4.436 \\
(3.055)\end{array}$ & $\begin{array}{c}3.183 \\
(1.361)\end{array}$ \\
\hline Overall Effects & $\begin{array}{c}0.401 \\
(1.168)\end{array}$ & $\begin{array}{c}3.067 \\
(6.313)\end{array}$ & $\begin{array}{l}-6.304 \\
(2.527)\end{array}$ & $\begin{array}{c}-0.337 \\
(0.538)\end{array}$ & $\begin{array}{l}-5.649 \\
(3.056)\end{array}$ & $\begin{array}{c}4.773 \\
(1.361)\end{array}$ \\
\hline
\end{tabular}

(1)The table simulates the welfare impacts on the average rural household of selected trade reforms. The Doha Development Agenda (DDA) involves the elimination of export subsidies and market access constraints in developed countries as well as partial liberalization of own tariffs in developing countries. Full Liberalization includes complete multilateral trade reforms. Own reforms involve the liberalization of own tariffs.

The consumption effects include first order effects (through budget shares) and consumption responses (through demand elasticities).

The income effects refer to wage agricultural income responses.

The Overall Effects are the sum of the consumption and income effects.

The Full Model is the joint model of demand and wages proposed here. The Alternative Methodologies include Deaton elasticities (without the corrections of this paper) and the Naive wage agricultural model (that uses average cluster unit values as measured of prices.

The prices changes caused by the different trade reforms are calculated with the GTAP Computable General Equilibrium Model (CGE) in Hertel and Winters (2006). The price changes in the DDA, Full liberalization, and Own reform scenarios are, respectively: Corn, $0.4 \%, 14.6 \%,-3.7 \%$; Wheat, $0.4 \%, 14.6 \%,-3.7 \%$; Dairy, $0.2 \%,-0.6 \%,-11.5 \%$; Oils \& Fats, $3.0 \%, 15.2 \%,-3.4 \%$; Meat, $0.2 \%, 0.1 \%,-8.7 \%$; Fruits \& Vegetables, $0.6 \%,-1.8 \%,-3.4 \%$.

Standard errors in parenthesis. 